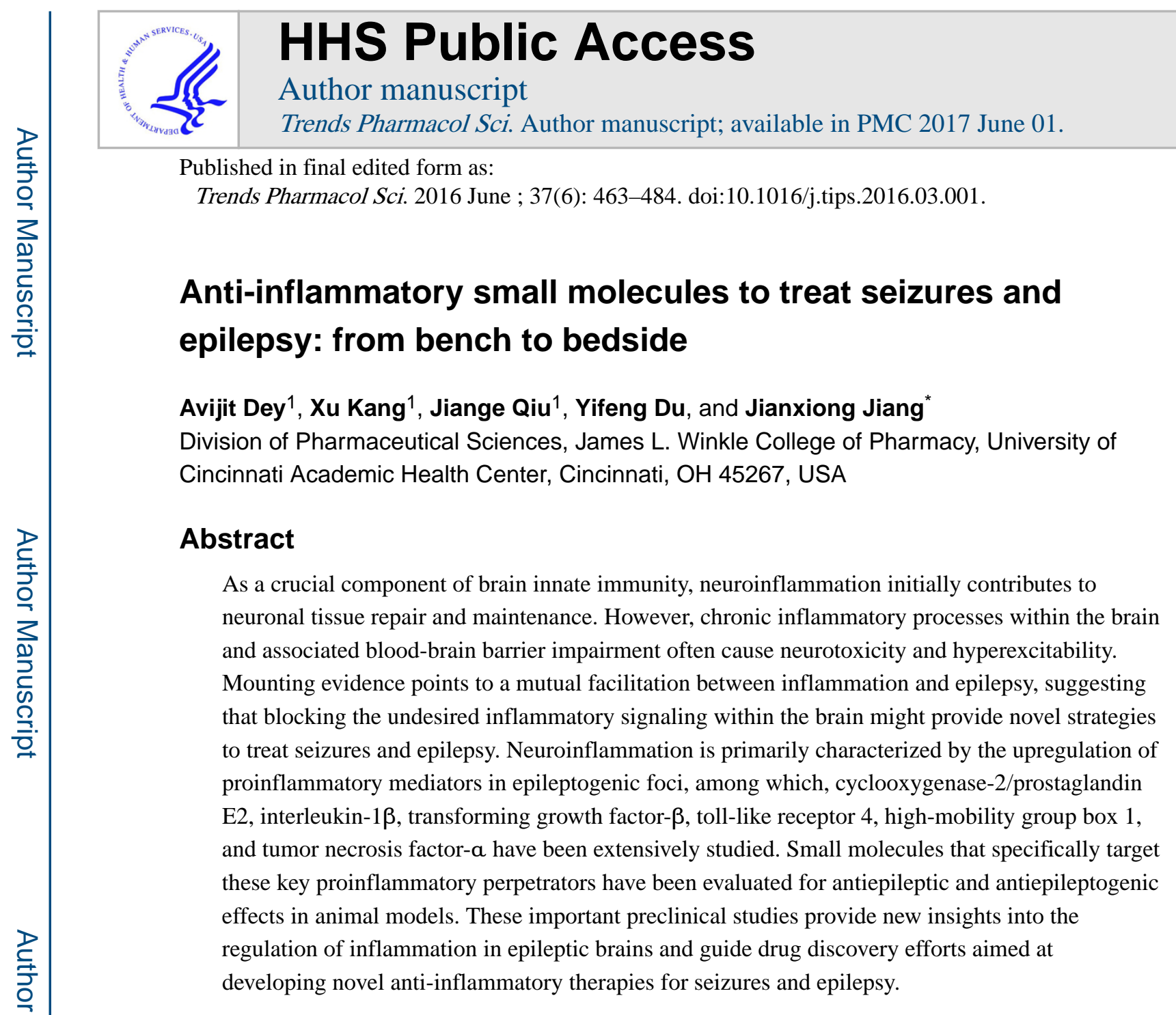

Keywords

Epilepsy; Epileptogenesis; Interleukin; Neuroinflammation; Prostaglandin; Seizure

\title{
Neuroinflammation and Epilepsy
}

Inflammation is a sequence of biological responses to pathogenic challenges, and in the periphery, it is often symptomized by local redness, fever, swelling, pain and loss of function. The inflammatory processes can be temporally classified as either acute or chronic. During the acute phase of inflammation, plasma proteins and leukocytes from the blood vessels rapidly extravasate to the injury sites to initiate a series of biochemical and cellular events, involving the immune system, vasculature and local cells. As a key component of innate immunity, acute inflammation represents an attempt to resolve the noxious stimuli

*Correspondence: jianxiong.jiang@uc.edu (J. Jiang).

${ }^{1}$ Co-first author

Publisher's Disclaimer: This is a PDF file of an unedited manuscript that has been accepted for publication. As a service to our customers we are providing this early version of the manuscript. The manuscript will undergo copyediting, typesetting, and review of the resulting proof before it is published in its final citable form. Please note that during the production process errors may be discovered which could affect the content, and all legal disclaimers that apply to the journal pertain. 
and initiate the healing process [1]. Acute inflammation typically subsides in days; however, under certain circumstances inflammation persists to become chronic. Although tissue healing continues at the chronic stage of inflammation, the excessive inflammatory processes promote a complex network of molecular and cellular signaling pathways that are linked to debilitating conditions such as rheumatoid arthritis, pain, cancer, vascular diseases, skin inflammation, diabetes, heart diseases and pulmonary diseases [2]. In contrast to our historical understanding that the central nervous system (CNS) is immune-privileged due to tight constriction of the blood-brain barrier (BBB), inflammation within the brain - or neuroinflammation - has emerged as a salient feature in virtually all neurological conditions (Box 1), and been proposed to facilitate disease progression in the CNS (Box 2). Over the past decade, an increasing body of clinical and preclinical evidence points to the involvement of inflammation in the pathophysiology of acute brain insults and subsequent epileptogenesis, a process that a normal brain becomes epileptic (Box 2) [3-6], and antiinflammatory therapeutics targeting crucial inflammatory components have been proposed to treat seizures and epilepsy [7-13]. In this review, we highlight our current understanding of neuroinflammation in epilepsy by focusing on recent preclinical efforts to develop antiinflammatory therapies that block acute seizures and/or the development of epilepsy via selective small molecules.

\section{Box 1}

\section{Does seizure cause neuroinflammation?}

Neuroinflammation is characterized by the activation of microglia, astrocytes, endothelial cells of the BBB, infiltration of plasma proteins and immune cells - granulocytes (mainly neutrophils) in the beginning, followed by monocytes within a day and lymphocytes days later, and the upregulation of an array of pro- or anti-inflammatory mediators [5, 163165]. The best-known members of these inflammatory molecules can be classified into proinflammatory enzymes including COX-2, inducible NOS (iNOS) and NOX; cytokines such as IL-1 $\beta$, IL-6, TNF- $\alpha$; and growth factors like TGF- $\beta$ and BDNF. These cellular and biochemical alterations within the brain are commonly observed in brain specimens from epilepsy patients and in brain tissues from animals with experimental epilepsy [3, 4]. In addition, recent studies show that seizures also can increase the BBB permeability, which can intensify and perpetuate neuroinflammation via extravasation of leukocytes and inflammatory molecules from blood vessels into the brain parenchyma [5, 164, 166]. In general, initial prolonged seizures can trigger acute immune and inflammatory responses within the brain, while the subsequent spontaneous recurrent seizures sustain the chronic neuroinflammation.

\section{Box 2}

\section{Does neuroinflammation cause seizure?}

Neuroinflammation appears to affect seizure severity and recurrence, which is evident by extensive clinical and experimental data. Patients with autoimmune diseases and encephalitis accompanied by severe and long-lasting neuroinflammation often have high frequency of seizures $[167,168]$; infections in the CNS - caused by viruses, bacteria and 
parasites - often lead to severe inflammatory reactions and are a major risk factor for epilepsy, as about $6.8-8.3 \%$ of survivors of CNS infections have unprovoked seizures in developed countries and the rates are much higher in the developing world [169]. These clinical observations clearly suggest that the immune and inflammatory processes are involved in some forms of epilepsy. It now becomes clear that proinflammatory mediators such as COX-2, PGE 2 , IL-1 $\beta$, IL-6, HMGB1, TLR4, TNF- $\alpha$, TGF- $\beta$ and NOX2 play important roles in seizure generation and exacerbation [3, 13, 74, 132]. For instance, systemic inflammatory processes induced by fever in children can cause seizures and the proinflammatory cytokines such as IL-1 $\beta$ are believed to play crucial roles [170]. Furthermore, systemic administration of LPS in rodents can change the seizure threshold [171] and enhances epileptogenesis [82, 172], also involving cytokines IL- $1 \beta$ and TNF- $\alpha$, and COX-2 activation in the brain. Thus, as a consequence of epilepsy, neuroinflammation in turn can cause or facilitate epilepsy.

\section{Small Molecules as Anti-Inflammatory Therapeutics}

Small molecules are synthetic chemicals with a low molecular weight ( $<900 \mathrm{Da})$ and a size on the order of a nanometer. These organic compounds constitute the vast majority of current drugs in the market. Due to the small size, they are widely distributed throughout the body after administration and can cross biological membranes, thereby modulating a broad range of intracellular and extracellular molecular targets. Compared to biological drugs like recombinant proteins, peptides, monoclonal antibodies, etc., small molecule-based drugs provide many manufacture and delivery advantages: they are typically low-cost, stable, nonimmunogenic, easy to characterize and modify, orally available, and capable of penetrating tissues [14]. The future of small-molecule paradigm is still promising particularly in the CNS field in that biological drugs generally have poor brain penetration. Up to date, a number of small-molecule compounds that selectively modify the key inflammatory signaling pathways have been evaluated for therapeutic benefits in animal models of seizures and epilepsy, with more under development or to be tested. Most of these compounds have sufficient pharmacodynamic and pharmacokinetic properties - i.e., potency, selectivity, bioavailability, in vivo half-life, brain penetration - and are considerably safe with appropriate dosage and dosing paradigm, and thus have enormous translational potential, as some compounds have advanced to clinical studies.

\section{COX Inhibitors}

Cyclooxygenase (COX) is the rate-limiting enzyme in the synthesis of prostanoids that comprise prostaglandin $\mathrm{D} 2\left(\mathrm{PGD}_{2}\right), \mathrm{PGE}_{2}, \mathrm{PGF}_{2 \mathrm{a}}$ and $\mathrm{PGI}_{2}$, and thromboxane A2 $\left(\mathrm{TXA}_{2}\right)$. COX has two isoforms: COX-1 is constitutively expressed throughout the body to maintain homeostatic prostaglandins, which are important for many normal physiological functions; COX-2 is usually undetectable in most normal tissues but strongly induced by infection, fever, inflammation and other stimuli such as growth factors and excessive neuronal activity, and is generally considered as a major proinflammatory mediator. COX-2 is rapidly and robustly induced within the brain following seizures in both human patients and experimental animals [15-17]. Chronic upregulation of COX-2 perpetuates and aggravates 
neuroinflammation and, thus contributes to the pathophysiology of acute and chronic seizures. The first insight into the pathogenic role for COX-2 in seizures was derived from experimental evidence that neuronal overexpression of COX-2 facilitates kainate-provoked convulsions and increases seizure-associated mortality in mice [18]. Additional evidence from a genetic strategy came from COX-2 knockout mice that show reduction of recurrent hippocampal seizures in the kindling model of status epilepticus (SE) [19], and resistance to neuronal death after kainate treatment [20]. More recently, in the mouse pilocarpine model, ablation of COX-2 from a restricted population of forebrain neurons reduced neuroinflammation and secondary neurodegeneration [16], and subtly improved retrograde memory performance [21]. Multiple COX-2-selective and nonselective inhibitors including aspirin, celecoxib, etoricoxib, indomethacin, nimesulide, NS398, parecoxib (valdecoxib), rofecoxib, SC58236, SC58125 (Figure 1), have been evaluated for antiepileptic and antiepileptogenic effects, neuroprotection, and improvements in behavioral and cognitive abnormalities in chemoconvulsant or electrical models of acute seizures and epilepsy (Table 1) $[9,19,20,22-37]$.

Interestingly, it appears that treatment with these COX-2 inhibitors beginning after - but not before - SE onset usually shows beneficial effects including reductions in neuronal damage, recurrent seizures and behavior abnormalities (Table 1). The inadequate therapeutic outcomes from preadministration of COX-2 inhibitors in animal SE models have been known for nearly two decades [22]. For instance, treatment by NS398, the first documented small molecule that selectively inhibits COX-2, beginning five hours after but not 30 minutes before kainate injection is neuroprotective in rats [20]. Similarly, celecoxib, the first COX-2 selective inhibitor to reach market, when administered once daily $(6 \mathrm{mg} / \mathrm{kg}$, i.p.) for five days after but not before kainate injection in rats, significantly attenuates brain-derived neurotrophic factor (BDNF) induction in hippocampus and reduces the learning and object exploration deficits in Morris water maze task [26]. In another study, oral administration of celecoxib (20 mg/kg) one day after a one-hour episode of lithium/pilocarpine-induced SE in rats reduces spontaneous recurrent seizures, and prevents neuronal death and microglia activation in the hippocampus [27]. Furthermore, nonselective COX inhibitor aspirin, when administered commencing hours after pilocarpine-induced SE, reduces neuronal damage in hippocampus and recurrent seizures in rats [23], whereas aspirin pre-treatment beginning three days before pilocarpine injection does not show such beneficial effects but increases the seizure susceptibility in mice [24].

These seemingly conflicting outcomes by pre- and post-treatment of COX-2 inhibitors suggest a possible dual consequence of COX-2 induction - early neuroprotection and later neurotoxicity involving persistent inflammation following brain insults. This is also evident by a trend of aggregating hippocampal injury detected one day after pilocarpine-induced SE in mice with COX-2 deficiency in forebrain neurons, but a substantial neuroprotection measured three days later [16]. In addition, the dosage, dosing interval, dosing duration, as well as the pharmacodynamics and pharmacokinetics of test compounds such as off-target activities and in vivo half-life could also potentially influence the therapeutic outcomes. Whether antiepileptic drugs (AEDs) are used to terminate seizures along with COX-2 inhibition in these animal studies is another potential contributory factor to the incongruent results [31, 32, 36, 37], in that long duration of SE - up to 10 hours in some cases - might 
impede the outcomes of COX-2 inhibition (Table 1). Nonetheless, the dichotomous actions of seizure-promoted COX-2 induction suggest that identifying the therapeutic time window and optimizing the treatment paradigm might help resolve the inconsistent efficacy of COX-2 inhibition in these animal models $[17,38]$.

Other than the desired inhibition on the synthesis of $\mathrm{PGE}_{2}$, the prostaglandin type that is largely responsible for COX-2 cascade-governed inflammation, COX-2 inhibition also causes collateral suppression of endothelial COX-2-derived $\mathrm{PGI}_{2}$, imposing vascular risks that discourage the clinical use of COX-2 inhibitors [39]. As such, rofecoxib (Vioxx ${ }^{\circledR}$ ) and valdecoxib (Bextra ${ }^{\circledR}$ ) were withdrawn from the USA market in 2004 and 2005, respectively, while celecoxib (Celebrex ${ }^{\circledR}$ or Onsenal ${ }^{\circledR}$ ) that is less COX-2 selective is still available to treat chronic conditions such as arthritis, pain and polyps, but with a black box warning for cardiovascular hazard. However, short-term and low-dose medication with selective COX-2 inhibitors is overall safe, evident by their negligible effects in control animals, and could be considered to treat seizure-promoted neuronal injury [40]. Nonetheless, the safety concerns raised on COX-2 inhibitors inspire that targeting a specific downstream prostaglandin synthase or receptor might offer an alternative strategy to control neuroinflammation and neuronal injury associated with seizures and epilepsy.

\section{Prostaglandin Receptor Antagonists}

As a major COX-2 product in the $\mathrm{CNS}, \mathrm{PGE}_{2}$ is now widely recognized for its crucial roles in neuroinflammation, neuronal hyperexcitability and excitotoxicity, via promoting local vasodilation, infiltration of immune cells, and upregulation of many proinflammatory mediators in the inflamed brain regions (Figure 2A) [40, 41]. Interestingly, the anticonvulsant action of COX-2 inhibitor celecoxib in pentylenetetrazol-induced seizures can be reversed by intracerebroventricular administration of $\mathrm{PGE}_{2}$ [28], suggesting that COX-2 facilitates seizures through $\mathrm{PGE}_{2}$. Conversely, another prostaglandin type $\mathrm{PGD}_{2}$ has been demonstrated to show antiepileptic effect via the DP1 receptor after pentylenetetrazol administration in both rats and mice $[42,43]$. Likewise, intracisternal administration of $\mathrm{PGF}_{2 a}$ reduces seizure intensity and mortality after kainate injection in mice [44]. Therefore, targeting specific $\mathrm{PGE}_{2}$ receptors instead of COX-2 enzyme itself could avoid compromising the $\mathrm{PGD}_{2}$ - or $\mathrm{PGF}_{2 a}$-mediated anti-seizure effects.

$\mathrm{PGE}_{2}$ acts on four $\mathrm{G}$ protein-coupled receptors (GPCRs), namely EP1, EP2, EP3 and EP4 (Figure 2A). Over the past decade, studies have demonstrated that genetic ablation or pharmacological inhibition of $\mathrm{G}_{\mathrm{aq}}$-coupled $\mathrm{EP} 1$ receptor is neuroprotective following experimental ischemic injuries [45-48]. These results from ischemia models suggest that the EP1 receptor might contribute to $\mathrm{PGE}_{2}$-mediated neurotoxicity. In addition, EP1 receptor activation plays an important role in the BBB impairment following ischemic strokes [49]. A recent study revealed that global ablation of EP1 receptor reduces seizure threshold, neuronal damage and proinflammatory responses in hippocampus after kainate injection in mice [50]. Furthermore, the EP1-selective antagonist SC-51089 (Figure 2B) can abolish the seizure-induced upregulation of the BBB efflux transporter P-glycoprotein following pilocarpine-induced SE in rats, suggesting that EP1 receptor antagonism by small molecules might facilitate the access and efficacy of therapeutic agents such as phenytoin via restoring 
the BBB integrity [51]. Systemic pre-treatment with SC-51089 only moderately decreases the seizure severity without affecting the seizure threshold in amygdala-kindled mice [25], indicating that the EP1 antagonist alone may not afford sufficient anti-seizure effects.

$\mathrm{PGE}_{2}$ via the $\mathrm{G}_{\mathrm{as}}$-coupled $\mathrm{EP} 2$ receptor at basal level mediates some normal physiological function; however, mounting evidence provides strong support for a link between the EP2 receptor activation and the secondary neurotoxicity in models of chronic inflammation and neurodegeneration (Figure 2A) [41, 52-54]. Thus, selective EP2 antagonism by small molecules has been proposed to prevent COX-2 cascade-governed pathogenesis in the CNS. A number of potent and selective antagonists for EP2 receptor have been developed in the past few years (Figure 2C) [52, 55]. For instance, compound TG4-155, an EP2-competitive antagonist identified by high-throughput screening (HTS), shows a Schild $K_{\mathrm{B}}$ of $2.4 \mathrm{nM}$ on human EP2 receptor and good selectivity against other prostanoid receptors with a plasma half-life of 0.6 hour and a brain-to-plasma ratio of 0.3 in mice [56, 57]. TG4-155 attenuates the induction of COX-2 and other proinflammatory mediators caused by EP2 receptor activation in rat microglia $[53,56]$. Intraperitoneal administration of TG4-155 $(5 \mathrm{mg} / \mathrm{kg})$ in mice one hour and again 12 hours after termination of pilocarpine-induced SE reduces neuronal injury in the hippocampus [56]. Another EP2 antagonist, TG6-10-1, was created by introducing a trifluoromethyl group in the methylindol ring of TG4-155, aiming to improve its pharmacokinetics (Figure 2C) [58]. This chemical modification indeed substantially improves its plasma half-life to 1.6 hours and the brain-to-plasma ratio to 1.6 in mice without markedly compromising the potency and selectivity [56, 57, 59], enabling TG6-10-1 suitable for more extensive in vivo testing. Systemic administration of TG6-10-1 $(5 \mathrm{mg} / \mathrm{kg}$, i.p.) beginning two to four hours, but not one or 21 hours, after pilocarpine SE onset in mice reduces delayed mortality, accelerates recovery from weight loss and functional loss, prevents the BBB impairment, and reduces neuroinflammation and neuronal injury in the hippocampus [17, 59]. These studies also uncover a therapeutic time window for using TG6-10-1 to suppress seizure provoked-neuroinflammation that coincides with the timecourse of COX-2 induction, taking into account the compound pharmacokinetics [38]. Furthermore, administration of TG6-10-1 is also neuroprotective and accelerates functional recovery in rats following SE induced by acute exposure to diisopropyl fluorophosphate (DFP), an analog of nerve agent sarin [60]. Intriguingly, treatment with TG6-10-1 doesn't modify seizures acutely $[59,60]$, suggesting that these benefits from EP2 inhibition after SE are not caused from a direct anticonvulsant effect, rather likely derive from an antiinflammatory action. To move these EP2 antagonists toward clinical studies, future efforts in medicinal chemistry and drug formulation are required to further improve their in vivo halftime without affecting their desirable potency, selectivity and brain-to-plasma ratio [61-63].

Whether these EP1 and EP2 receptor antagonists have effect on chronic epilepsy or cognitive deficit after SE awaits further investigation with long-term electroencephalogram (EEG) recording. Nonetheless, these preclinical studies suggest that $\mathrm{PGE}_{2}$ signaling pathways via EP1 and EP2 receptors are critically involved in neuroinflammation and neurodegeneration after seizures, and point to EP1 and/or EP2 antagonism as a possible adjunctive therapeutics - for the well-documented neuroprotection - to treat SE, along with the current first-line AED therapies [11]. Other prostaglandin receptors such as EP3, EP4 
and FP also contribute to inflammation in both the periphery and the brain (Figure 2A) [6466]. Whether the activation of these receptors is proconvulsant as well remains unknown.

\section{IL-1 $\beta$ Synthesis Inhibitors and Receptor Antagonists}

Proinflammatory cytokines such as interleukin-1 $\beta$ (IL-1 $\beta$ ), IL-6 and tumor necrosis factor- $a$ (TNF-a) normally express at low basal levels in the brain and are rapidly upregulated in response to acute brain insults like seizures. Elevated expression of IL-1 $\beta$, its receptor type 1 (IL-1R1), as well as its biosynthetic enzyme - caspase-1/interleukin converting enzyme (ICE) have been reported in both glia and neurons in human epilepsy foci from pharmacoresistant forms of symptomatic epilepsies and in experimental models of seizures and epilepsy [67-70]. Pharmacological and genetic interventions in animal models showed that this cytokine contributes to pathophysiology of epilepsy in multiple ways: i). increases neuronal hyperexcitability via blocking astrocyte-mediated reuptake of glutamate from the synaptic space [71]; ii). enhances NMDA receptor function through activation of Src tyrosine kinases and subsequent NR2A/B subunit phosphorylation [72]; iii). alters GABAergic neurotransmission [73]; iv). modulates voltage-gated ion channels and contributes to channelopathies [74]. In addition, Caspase-1 activation has been recently demonstrated to promote the secretion of high-mobility group box 1 (HMGB1) [75], a proinflammatory molecule also implicated in seizure generation [76-78]. Intrahippocampal administration of IL-1 receptor antagonist (IL-1RA) or its overexpression in astrocytes inhibits behavioral and electrographic seizures triggered by injection of kainate or bicuculline, or electrical stimulation of the hippocampus in mice [79, 80]. In addition, intravenous administration of IL-1RA reduces SE onset and the BBB disruption in rat lithium/pilocarpine model of SE [81]. Moreover, IL-1RA also reduces the augmentation of epileptogenesis enhanced by lipopolysaccharide (LPS) - a classical inducer of immune and inflammatory responses [82], suggesting that blocking IL-1 $\beta$ signaling might prevent SE and chronic epilepsy.

HMR 3480/VRT-18858 and VRT-043198 are selective inhibitors of caspase-1/ICE that cleaves IL-1 $\beta$ precursor (pro-IL-1 $\beta$ ) into active mature IL-1 $\beta$ (Figure 3) [83]. In the periphery, VX-740 (pralnacasan) - a pro-drug of HMR 3480/VRT-18858 - can reduce joint damage in two mouse models of osteoarthritis [84], and attenuate dextran sulfate sodiuminduced colitis and T helper 1 T-Cell activation in mice [85]. Pro-drug VX-765 can be efficiently converted to VRT-043198 when administered systemically to mice and inhibits LPS-induced IL-1 $\beta$ secretion. VX-765 also reduces disease severity of rheumatoid arthritis in mice and cytokine secretion in a mouse model of skin inflammation [86]. These studies on peripheral inflammation in mice suggest that inhibition of IL-1 $\beta$ synthesis is sufficient to block excessive inflammatory processes. In the CNS, treatment with VX-765 $(50 \mathrm{mg} / \mathrm{kg}$, i.p.) decreases chronic stress-induced depressive symptom in mice with reduced serum and hippocampal IL-1 $\beta$ levels [87]. Interestingly, administration of VX-740 (50 $\mu$ g, i.c.v.) or VX-765 (25-200 mg/kg, i.p.) decreases seizure-induced IL-1 $\beta$ production in the hippocampus, delays SE onset, and reduces seizure duration in rats with intrahippocampal injection of kainate. These beneficial effects are associated with caspase- 1 inhibition and blockade of IL- $1 \beta$ biosynthesis in the brain, and recapitulated in mice that lack caspase-1 [88]. In addition, caspase-1 inhibition by VX-765 (200 mg/kg, i.p.) suppresses 
epileptogenesis in rat hippocampal kindling model by blocking astrocytic IL- $1 \beta$ production [89]. Furthermore, systemic administration of VX-765 shows powerful anticonvulsant activity on acute seizures and in chronic epileptic mice that are refractory to conventional AEDs in a dose-dependent manner [90]. These results taken together strongly support that pharmacological inhibition of caspase- 1 by selective small molecules represents a possible therapeutic strategy to suppress acute seizures and the development of epilepsy [13].

\section{TGF- $\beta$ Signaling Inhibitors}

Transforming growth factor- $\beta$ (TGF- $\beta$ ) is a multifunctional cytokine that mediates essential roles in cell proliferation and differentiation, apoptosis, embryogenesis and inflammatory responses [91]. TGF- $\beta$ dimers first activate a type II receptor (T $\beta$ RII), which in turn phosphorylates a type I receptor (T $\beta$ RI) or activin-like kinase 5 (ALK5). The phosphorylated ALK5 then activates the intracellular SMAD protein complexes and multiple mitogen-activated protein kinase (MAPK) pathways to regulate a wide range of downstream signaling pathways [91, 92]. In addition, ALK5-dependent TGF- $\beta$ signaling can regulate the late stages of adult hippocampal neurogenesis, suggestive of its involvement in neurogenesis during aging and disease [93]. Recent studies provide evidence that TGF- $\beta$ signaling is involved in epileptogenesis after brain injury associated with the BBB destruction [94]. Shortly after the BBB function is compromised, albumin begins to enter the brain's extracellular space [95], and induces activation of TGF- $\beta$ signaling in astrocytes, causing astrocytic activation, impaired potassium buffering and glutamate metabolism, upregulation of proinflammatory cytokines, and synaptogenesis that eventually result in increased neuronal excitability and spontaneous seizures [96-98]. Moreover, activation of the astrocytic TGF- $\beta$ /ALK5 pathway by the intracerebroventricular infusion of albumin induces excitatory - but not inhibitory -synaptogenesis prior to the appearance of spontaneous seizures. Interestingly, the albumin-initiated synaptogenesis and seizures can be abolished by SJN2511 (RepSox) (i.c.v.), a potent and selective TGF- $\beta$ /ALK5 inhibitor (Figure 4) [99]. In addition, albumin-induced TGF- $\beta$ upregulation and associated SMAD2/3 phosphorylation are blocked by the ALK5 antagonists -SJN2511 or SB431542 (Figure 4) [100]. Furthermore, losartan (Figure 4), a USA FDA-approved small-molecule antagonist for angiotensin II receptor type $1\left(\mathrm{AT}_{1}\right)$ that has been reported to block the peripheral TGF- $\beta$ signaling, can effectively suppress albumin-induced TGF- $\beta$ activation in the brain and prevent the subsequent spontaneous seizures [100]. These results reinforce the notion that targeting TGF- $\beta$ signaling is a feasible strategy for disease modification and prevention of epilepsy.

\section{NOX2 Inhibitors}

Oxidative stress in the brain is caused by the imbalance between the generation and detoxification of reactive oxygen and nitrogen species (ROS/RNS) that attack brain cells and thus play important roles in brain inflammation, aging and degeneration [101]. Activated NADPH oxidases (NOXs) - a family including NOX1, NOX2, NOX3, NOX4, NOX5, dual oxidase 1 (DUOX1) and DUOX2 - are a primary source of ROS via transporting electrons from intracellular NADPH, across biological membrane, and then to extracellular oxygen, generating superoxide $[102,103]$. Among these seven isozymes, NOX2 is the prototype 
form and plays central roles in neuroinflammation, neurodegeneration and associated functional deficits in neurological conditions such as spinal cord injury [104], Parkinson's disease [105, 106], Alzheimer's disease (AD) [107], amyotrophic lateral sclerosis [108], multiple sclerosis [109], and epilepsy [110].

Evidence suggests that seizure-induced neuronal damage in the hippocampus is associated with ROS induction after pilocarpine injection in rats, characterized by a decrease in reduced glutathione level and increases in nitrite content and lipid peroxidation [111]. Likewise, kainate-induced SE in rats results in a time-dependent translocation of NOX subunits (gp91 ${ }^{\text {phox }}, \mathrm{p} 47^{\text {phox }}, \mathrm{p} 7^{\text {phox }}$ and rac-1) from hippocampal cytosol to membrane where active NOX complex is assembled. Interestingly, the seizure-induced NOX activation coincides with microglial activation in the hippocampus [112]. Furthermore, ROS generated by NOX contributes to neurodegeneration in pilocarpine-treated rats, which is substantially suppressed by apocynin -a selective NOX2 inhibitor (Figure 5) [113]. In another study, apocynin - when systemically administered at two and 24 hours after lithium/pilocarpineinduced SE in rats - reduced seizure-induced ROS production, lipid peroxidation, BBB disruption, neutrophil infiltration, microglial activation and neuronal death [114]. There thus is a growing interest in NOX2 as therapeutic target for seizures and epilepsy. However, apocynin and other historical NOX2 inhibitors including diphenyleneiodonium (DPI) are often challenged for their off-target activities (Figure 5). For instance, apocynin shows marked ROS scavenging activity and inhibition on rho kinases; DPI is a general inhibitor of flavoproteins, e.g., xanthine oxidase and endothelial nitric oxide synthase (eNOS) [115]. Owing to recent advances in chemical biology and HTS, several new classes of smallmolecule NOX inhibitors with improved specificity have been identified [115-117]. However, whether these novel NOX2 inhibitors would show any antiepileptic or antiepileptogenic effect in animal models requires investigation.

\section{Other Potential Anti-Inflammatory Targets for Small Molecules}

\section{Lipoxygenase (LOX)}

Similar to prostaglandins, leukotrienes produced by LOX from arachidonic acids are also proinflammatory and increase microvascular permeability, therefore drugs that are able to inhibit both COX and LOX are proposed to treat inflammation-associated conditions due to their dual actions [118]. For instance, natural product flavonoids containing baicalin and catechin show neuroprotection during kainate-induced excitotoxicity via reducing both COX-2 and 5-LOX activities [119]. Likewise, licofelone (Figure 1), a dual COX/LOX smallmolecule inhibitor, which recently was approved as an effective treatment for osteoarthritis, shows anticonvulsant effect in a mouse pentylenetetrazol seizure model [120].

\section{Microsomal prostaglandin E synthase-1 (mPGES-1)}

PGES is the enzyme that produces $\mathrm{PGE}_{2}$ from $\mathrm{PGH}_{2}$, a precursor molecule directly synthesized by COX, and has three isozymes: mPGES-1 (or PTGES), mPGES-2 (or PTGES2) and cytosolic PGES (cPGES or PTGES3) (Figure 2A). Among these, mPGES-1 is inducible, membrane-bound, and functionally linked to COX-2 in preference to COX-1 [40]. mPGES-1 promotes inflammatory and pain reactions via synthesis of $\mathrm{PGE}_{2}$ in a disease 
model of human rheumatoid arthritis [121]. In the CNS, mPGES-1 is upregulated in pyramidal neurons of AD human patients and transgenic mice [122-124], and contributes to pathogenesis of $\mathrm{AD}[123,124]$. In addition, mPGES-1 exacerbates inflammation and demyelination via disrupting the local vessel structure in a model of multiple sclerosis [125]. mPGES-1 is also robustly induced in mice following pilocarpine-induced seizures and aggravates neuronal loss induced by kainate, suggesting that mPGES-1 is involved in seizure-triggered pathogenesis [17, 126, 127]. mPGES-1 also has been shown to exacerbate epileptic seizures and hippocampal gliosis in mouse pentylenetetrazol seizure model [128]. The first clinical trial with the mPGES-1 inhibitor LY3023703 (structure not disclosed) by Eli Lilly and Company (https://clinicaltrials.gov/show/NCT01872910) reveals more potent inhibition of $\mathrm{PGE}_{2}$ synthesis than COX-2 inhibitor celecoxib without decreasing $\mathrm{PGI}_{2}$ levels in the blood [129]. Thus, blockade of mPGES-1 by small molecules should be explored as an anti-inflammatory therapy for epilepsy in the future $[128,130]$.

\section{Toll-like receptor 4 (TLR4)}

Toll-like receptors (TLRs) have significant homology in the cytosolic region to the IL-1R family and, thus shares partly overlapping signaling molecules with IL-1 $\beta / I L-1 R$ [131]. Among TLR family members, TLR4 is the LPS sensing receptor and a crucial component of innate immunity. TLR4 can be activated by HMGB1, an endogenous danger signal protein released by immune cells or by neurons and glia in the CNS in response to cell damage or neuronal hyperexcitability. Interestingly, both HMGB1 and TLR4 are upregulated in brain specimens from epilepsy patients and in brain tissues from animals with chronic seizures [3, 132]. HMGB1, particularly the active disulfide form, enhances NMDA receptor function and excitotoxicity, as well as exacerbates kainate-induced seizures by activating TLR4 in hippocampal neurons $[76,78]$. On the other hand, HMGB1 also activates the receptor for advanced glycation end products (RAGE), contributing to hyperexcitability and proictogenic effects that are TLR4-independent [77]. Antagonism of HMGB1/TLR4 signaling by pseudopeptide BOX A or LPS-RS - an inactive LPS from photosynthetic bacterium Rhodobacter sphaeroides - reduces initial and chronic seizures. Moreover, TLR4 knockout mice show resistance to kainate-induced seizures [76]. Intriguingly, TLR4 has been reported to upregulate COX-2 expression via activation of the immune and inflammatory transcription factor - nuclear factor- $\mathrm{\kappa B}$ (NF- $\mathrm{\kappa B}$ ) in several models of inflammation and injury [133-135]. Therefore, the HMGB1/TLR4 signaling has been proposed as antiepileptic and antiepileptogenic target $[13,136]$. However, LPS-RS has poor pharmacokinetics, e.g., low brain penetration. Another LPS-mimicking antagonist eritoran recently failed in a multinational Phase III clinical trial for severe sepsis (https:/clinicaltrials.gov/show/ NCT00334828). As an alternative strategy, small-molecule inhibitors (e.g., TAK-242) that target TLR4 have been developed. However, test of these novel TLR4 antagonists in animal models of acute seizures or epilepsy has not been reported to date.

\section{TNF-a}

TNF- $\alpha$ is a crucial proinflammatory cytokine that belongs to the TNF superfamily of ligands, which are involved in the activation, differentiation, proliferation and infiltration of immune cells into the CNS during systemic inflammation [137]. Systemic administration of TNF- $a 24$ hours after amygdala kindling in rats facilitates the behavioral seizures and 
increases the epileptiform discharges, while the electrical stimulation in turn significantly enhances TNF- $a$ levels in both blood and the brain, suggesting a mutual facilitative interaction between seizure and proinflammatory cytokines [138]. Intriguingly, it becomes clear that TNF-a plays a dichotomous role in the pathophysiology of seizures and epilepsy pro-convulsive effect through TNF receptor type 1 (TNFR1 or p55) and anti-convulsive effect via receptor 2 (TNFR2 or p75), depending on engaged cellular context [139-142]. Therefore, inhibition of TNFR1 and/or activation of TNFR2 represents a novel strategy to treat neurological conditions including epilepsy $[11,13]$. In fact, a PEGylated TNFR1selective antagonistic TNF mutant (PEG-R1antTNF) suppresses arterial inflammation [143], whereas a specific TNFR2 agonist - TNC-scTNF(R2) can protect human dopaminergic neurons from oxidative stress-induced cell death [144]. However, small molecules that specifically modulate TNFR1 or TNFR2 with sufficient pharmacodynamics and pharmacokinetics are not available.

\section{IL-6}

IL-6 regulates inflammatory and immune responses through its receptor (IL6R or CD126) that is coupled to gp130 (CD130). Like other prototypical proinflammatory cytokines such as IL-1 $\beta$ and TNF- $\alpha$, IL- 6 signaling also can induce COX-2 to synthesize PGE $_{2}$ via activating NF- $\mathrm{kB}$ transcriptional signaling [145-147]. IL-6 induction is widely observed in epilepsy patients and in animal models of experimental epilepsy [3, 148]. Recent evidence in the clinical setting and experimental models suggests active roles of IL-6 in seizure generation and exacerbation [149]. For example, intranasal administration of recombinant IL-6 one hour before systemic injection of pentylenetetrazol exacerbates the severity of seizures in rats [150]. The proconvulsant action of IL- 6 is also supported by extensive studies on IL-6 deficient mice [151, 152] and IL-6 overexpressing mice [153], and is presumably associated with a constitutive loss of inhibitory interneuron function [153]. Future efforts should be directed toward developing potent and selective small molecules that target the synthesis of IL-6 or its downstream receptor IL6R, and evaluating their antiepileptic and antiepileptogenic effects in animal models.

\section{Concluding Remarks}

Current anti-inflammatory therapies in epilepsy are limited to immunosuppressants such as adrenocorticotropic hormone, immunoglobulin, plasmapheresis, monoclonal antibodies and corticotropic steroid hormones $[154,155]$. However these seldom-used treatments are restrictively effective for some specific types of epilepsy, e.g., those associated with severe encephalitis and autoimmune conditions, and their mechanism of action remains largely unknown $[3,154,155]$. Identifying key proinflammatory mediators involved in epilepsy and developing potent and brain-permeable small molecules that specifically modify their inflammatory functions might lead to novel antiepileptic and antiepileptogenic therapies. These efforts brought on a number of studies on pharmacological inhibition of several wellrecognized proinflammatory mediators by small molecules in animal models of acute seizures and epilepsy with many on the way. Particularly, the involvement of several prominent proinflammatory mediators - COX-2, PGE 2 , IL- $1 \beta$, IL6, TNF- $a$, TGF- $\beta$, NOX2, HMGB 1 and TLR4 - in initial seizures and chronic epilepsy has been extensively studied, 
and their pathogenic roles in the epileptic brain are becoming clear. However, more studies are imperative to determine whether any of small molecules targeting these proinflammatory mediators could successfully evolve into clinical innovations (see Outstanding Questions).

\section{OUTSTANDING QUESTIONS}

Does inflammation in the brain cause epileptic seizures and vice versa?

What are the limitations of current immunosuppressants for epilepsy treatment?

Why do current AEDs merely provide symptomatic relief rather than disease prevention or modification?

What are the feasible anti-inflammatory targets for treatment of seizures and epilepsy?

What are the current status and challenges for moving the experimental discoveries about small molecule-mediated anti-inflammatory therapeutics into a clinical setting?

What are the advantages of small molecules over the biological drugs for anti-inflammatory therapeutics in epilepsy treatment?

Activation of the COX-2 and prostaglandin cascade induces proinflammatory cytokines including IL-1 $\beta$, IL- 6 and TNF- $\alpha$, which in turn enhance COX- 2 transcription engaging the NF- $\mathrm{kB}$ pathway and, thus perpetuate inflammatory reactions in both periphery and brain [145-147, 156]. COX-2 inhibition by small molecules could break this self-reinforcing circle, thereby reducing chronic inflammation and subsequent sequelae (Figure 6). The studies on several COX-2 inhibitors in rodent models of seizures and epilepsy yielded some positive outcomes but discrepancy as well. Some COX-2 inhibitors, if not all, appear to confer anticonvulsant effects and reduce neuronal injury developing after SE when administered properly, although their moderate effects on behavioral and cognitive alterations need to be further characterized. A Phase IV clinical trial had been conducted to evaluate the antipyretic medication with a combination of selective and nonselective COX-2 inhibitors - diclofenac, paracetamol and ibuprofen - for preventing the recurrence of febrile seizures from 1997 to 2005 (https://clinicaltrials.gov/show/NCT00568217). This combined therapy failed to effectively prevent the recurrence of febrile seizures, nor did it reduce the body temperature in patients that had a febrile episode prior to a recurrent seizure [157]. However, the highest recommended doses with the rectal route of administration used in this study might have compromised the therapeutic outcomes because the high doses could increase the drug off-target activities and the rapid effects from rectal administration might impede the early benefits from COX-2 induction.

As a canonical marker of neuroinflammation, IL- $1 \beta$ is upregulated by seizures and initiates NF- $\kappa B$-dependent transcription of many proinflammatory genes including COX-2 and, therefore contributes to subsequent chronic epilepsy. VX-765, a small molecule that selectively blocks IL- $1 \beta$ synthesis, shows promising therapeutic effects in several rodent 
models of chronic epilepsy. To evaluate its safety, tolerability and proof-of-concept clinical activity, Vertex Pharmaceuticals initiated a randomized, placebo-controlled, double-blind study of VX-765 that involved 60 people with refractory partial onset epilepsy in 2010 (https://clinicaltrials.gov/show/NCT01048255). The results from this Phase II trial indicate a beneficial effect from a four-week treatment with VX-765 that occurred at the end of treatment period and continued during the beginning of the observation period, suggestive of a delayed mechanism of action from this compound [158]. This potential efficacy signal encouraged a longer-duration study to evaluate any more robust or additional clinical activity of VX-765. A larger Phase IIb trial therefore was launched in 2011 to further characterize VX-765 for a longer treatment period (https://clinicaltrials.gov/show/NCT01501383). Unfortunately, the trial was discontinued for administrative reasons. Nonetheless, VX-765 is generally tolerable and safe, and future study is necessitated to determine its efficacy in patients with refractory focal epilepsy [159]. As an alternative approach to the inhibition of IL-1 $\beta$ synthesis, blocking IL-1R1 -the effector for the inflammatory actions of IL-1 - might represent another anti-inflammatory strategy. For instance, a combined therapy with anakinra - a recombinant IL-1RA - and VX-765 shows marked neuroprotection in both rat lithium/pilocarpine and electrical SE models [160]. Likewise, anti-inflammatory drug cocktail containing anakinra, COX-2 inhibitor CAY10404 and caspase-1 expression inhibitor minocycline shows neuroprotective and antiepileptogenic effects in rat pups following lithium/pilocarpine SE [161]. However, current available therapies that directly inhibit IL-1 $\beta /$ IL-1R1 signaling are limited to neutralizing antibodies or peptides, as smallmolecule antagonists targeting IL-1R1 complex are not available at present [162].

In sum, accumulating evidence from preclinical and clinical studies suggests that targeting inflammatory signaling pathways represent a complementary approach for the current symptomatic therapies - AEDs - to control initial and recurrent seizures, particularly in epilepsy forms that are refractory to conventional treatments (Figure 6). The therapeutic strategy by resolving the brain inflammation could increase the seizure threshold and reduce the likelihood of spontaneous recurrent seizures, thereby providing disease prevention or modification rather than only symptomatic relief $[8,11,13]$. However, translating the antiinflammatory strategies to clinical uses is challenging and necessitates extra caution partially due to the complexity of inflammatory networks that are concurrently regulated by an array of components and signals that often reinforce each other. Combined therapies targeting multiple key proinflammatory molecules provide comprehensive suppression of inflammatory networks and thus might lead to more consistent and promising therapeutic outcomes (Figure 6) [119, 120, 160, 161]. Compared to biological drugs, brain-permeable small molecules are more realistic candidate agents for this therapeutic strategy due to their advantages in production, delivery and pharmacokinetics, and represent a future direction of developing novel therapeutics for epilepsy. As these small-molecule compounds continue growing, so too will our current understanding on chronic inflammatory processes in the epileptic brain, which will help to identify common pathophysiological mechanisms in different forms of epilepsy and ultimately lead to clinical innovations. 


\section{Acknowledgments}

We are very grateful to Annamaria Vezzani, Ph.D. and Michael Privitera, M.D. for insightful comments and constructive criticisms on an early draft of the manuscript. This work was supported by National Institutes of Health (NIH)/National Institute of Neurological Disorders and Stroke (NINDS) grant R00NS082379 (J.J.) and NARSAD Young Investigator Grant 20940 (J.J.) from the Brain \& Behavior Research Foundation.

\section{References}

1. Abbas, AK., et al. Basic Immunology: Functions and Disorders of the Immune System. Elsevier/ Saunders; 2012. Chapter 2 - Innate Immunity; p. 23-48.

2. Aoki T, Narumiya S. Prostaglandins and chronic inflammation. Trends in pharmacological sciences. 2012; 33:304-311. [PubMed: 22464140]

3. Vezzani A, et al. The role of inflammation in epilepsy. Nature reviews Neurology. 2011; 7:31-40. [PubMed: 21135885]

4. Aronica E, Crino PB. Inflammation in epilepsy: clinical observations. Epilepsia. 2011; 52(Suppl 3): 26-32. [PubMed: 21542843]

5. Marchi N, et al. Inflammatory pathways of seizure disorders. Trends in neurosciences. 2014; 37:5565. [PubMed: 24355813]

6. Wilcox KS, Vezzani A. Does brain inflammation mediate pathological outcomes in epilepsy? Advances in experimental medicine and biology. 2014; 813:169-183. [PubMed: 25012376]

7. D'Ambrosio R, et al. Novel frontiers in epilepsy treatments: preventing epileptogenesis by targeting inflammation. Expert review of neurotherapeutics. 2013; 13:615-625. [PubMed: 23738999]

8. Loscher W, et al. New avenues for anti-epileptic drug discovery and development. Nat Rev Drug Discov. 2013; 12:757-776. [PubMed: 24052047]

9. Rojas A, et al. Cyclooxygenase-2 in epilepsy. Epilepsia. 2014; 55:17-25. [PubMed: 24446952]

10. Vezzani A. Anti-inflammatory drugs in epilepsy: does it impact epileptogenesis? Expert opinion on drug safety. 2015; 14:583-592. [PubMed: 25645535]

11. Varvel NH, et al. Candidate drug targets for prevention or modification of epilepsy. Annual review of pharmacology and toxicology. 2015; 55:229-247.

12. Vezzani A, et al. Immunity and inflammation in status epilepticus and its sequelae: possibilities for therapeutic application. Expert review of neurotherapeutics. 2015; 15:1081-1092. [PubMed: 26312647]

13. Iori V, et al. Modulation of neuronal excitability by immune mediators in epilepsy. Curr Opin Pharmacol. 2016; 26:118-123. [PubMed: 26629681]

14. Samanen, J. Chapter 5 - Similarities and differences in the discovery and use of biopharmaceuticals and small-molecule chemotherapeutics. In: Ganellin, R.; Jefferis, SR., editors. Introduction to Biological and Small Molecule Drug Research and Development. Elsevier; 2013. p. 161-203.

15. Desjardins $P$, et al. Induction of astrocytic cyclooxygenase-2 in epileptic patients with hippocampal sclerosis. Neurochemistry international. 2003; 42:299-303. [PubMed: 12470703]

16. Serrano GE, et al. Ablation of cyclooxygenase- 2 in forebrain neurons is neuroprotective and dampens brain inflammation after status epilepticus. The Journal of neuroscience : the official journal of the Society for Neuroscience. 2011; 31:14850-14860. [PubMed: 22016518]

17. Jiang J, et al. Therapeutic window for cyclooxygenase-2 related anti-inflammatory therapy after status epilepticus. Neurobiol Dis. 2015; 76:126-136. [PubMed: 25600211]

18. Kelley KA, et al. Potentiation of excitotoxicity in transgenic mice overexpressing neuronal cyclooxygenase-2. The American journal of pathology. 1999; 155:995-1004. [PubMed: 10487857]

19. Takemiya T, et al. Inducible brain COX-2 facilitates the recurrence of hippocampal seizures in mouse rapid kindling. Prostaglandins \& other lipid mediators. 2003; 71:205-216. [PubMed: 14518562]

20. Takemiya T, et al. Prostaglandin E2 produced by late induced COX-2 stimulates hippocampal neuron loss after seizure in the CA3 region. Neuroscience research. 2006; 56:103-110. [PubMed: 16837093] 
21. Levin JR, et al. Reduction in delayed mortality and subtle improvement in retrograde memory performance in pilocarpine-treated mice with conditional neuronal deletion of cyclooxygenase-2 gene. Epilepsia. 2012; 53:1411-1420. [PubMed: 22780884]

22. Baik EJ, et al. Cyclooxygenase-2 selective inhibitors aggravate kainic acid induced seizure and neuronal cell death in the hippocampus. Brain research. 1999; 843:118-129. [PubMed: 10528118]

23. Ma L, et al. Aspirin attenuates spontaneous recurrent seizures and inhibits hippocampal neuronal loss, mossy fiber sprouting and aberrant neurogenesis following pilocarpine-induced status epilepticus in rats. Brain research. 2012; 1469:103-113. [PubMed: 22765917]

24. Jeong KH, et al. Influence of aspirin on pilocarpine-induced epilepsy in mice. The Korean journal of physiology \& pharmacology : official journal of the Korean Physiological Society and the Korean Society of Pharmacology. 2013; 17:15-21.

25. Fischborn SV, et al. Targeting the prostaglandin E2 EP1 receptor and cyclooxygenase-2 in the amygdala kindling model in mice. Epilepsy Res. 2010; 91:57-65. [PubMed: 20655707]

26. Gobbo OL, O'Mara SM. Post-treatment, but not pre-treatment, with the selective cyclooxygenase-2 inhibitor celecoxib markedly enhances functional recovery from kainic acid-induced neurodegeneration. Neuroscience. 2004; 125:317-327. [PubMed: 15062975]

27. Jung KH, et al. Cyclooxygenase-2 inhibitor, celecoxib, inhibits the altered hippocampal neurogenesis with attenuation of spontaneous recurrent seizures following pilocarpine-induced status epilepticus. Neurobiol Dis. 2006; 23:237-246. [PubMed: 16806953]

28. Oliveira MS, et al. Cyclooxygenase-2/PGE2 pathway facilitates pentylenetetrazol-induced seizures. Epilepsy Res. 2008; 79:14-21. [PubMed: 18255268]

29. Citraro R, et al. Antiepileptogenic effects of the selective COX-2 inhibitor etoricoxib, on the development of spontaneous absence seizures in WAG/Rij rats. Brain research bulletin. 2015; 113:1-7. [PubMed: 25701797]

30. Kunz T, Oliw EH. Nimesulide aggravates kainic acid-induced seizures in the rat. Pharmacology \& toxicology. 2001; 88:271-276. [PubMed: 11393589]

31. Trandafir CC, et al. Co-administration of subtherapeutic diazepam enhances neuroprotective effect of COX-2 inhibitor, NS-398, after lithium pilocarpine-induced status epilepticus. Neuroscience. 2015; 284:601-610. [PubMed: 25453777]

32. Polascheck N, et al. The COX-2 inhibitor parecoxib is neuroprotective but not antiepileptogenic in the pilocarpine model of temporal lobe epilepsy. Experimental neurology. 2010; 224:219-233. [PubMed: 20353773]

33. Kunz T, Oliw EH. The selective cyclooxygenase-2 inhibitor rofecoxib reduces kainate-induced cell death in the rat hippocampus. The European journal of neuroscience. 2001; 13:569-575. [PubMed: 11168565]

34. Akula KK, et al. Rofecoxib, a selective cyclooxygenase-2 (COX-2) inhibitor increases pentylenetetrazol seizure threshold in mice: possible involvement of adenosinergic mechanism. Epilepsy Res. 2008; 78:60-70. [PubMed: 18054463]

35. Kawaguchi K, et al. Cyclooxygenase- 2 expression is induced in rat brain after kainate-induced seizures and promotes neuronal death in CA3 hippocampus. Brain research. 2005; 1050:130-137. [PubMed: 15979590]

36. Holtman L, et al. Effects of SC58236, a selective COX-2 inhibitor, on epileptogenesis and spontaneous seizures in a rat model for temporal lobe epilepsy. Epilepsy Res. 2009; 84:56-66. [PubMed: 19186029]

37. Holtman L, et al. Cox-2 inhibition can lead to adverse effects in a rat model for temporal lobe epilepsy. Epilepsy Res. 2010; 91:49-56. [PubMed: 20643531]

38. Du Y, et al. Defining the therapeutic time window for suppressing the inflammatory prostaglandin E2 signaling after status epilepticus. Expert review of neurotherapeutics. 2016; 16:123-130. [PubMed: 26689339]

39. Funk CD, FitzGerald GA. COX-2 inhibitors and cardiovascular risk. J Cardiovasc Pharmacol. 2007; 50:470-479. [PubMed: 18030055]

40. Takemiya $\mathrm{T}$, et al. Roles of prostaglandin synthesis in excitotoxic brain diseases. Neurochemistry international. 2007; 51:112-120. [PubMed: 17629358] 
41. Andreasson K. Emerging roles of PGE2 receptors in models of neurological disease. Prostaglandins \& other lipid mediators. 2010; 91:104-112. [PubMed: 19808012]

42. Kaushik MK, et al. Prostaglandin D(2) is crucial for seizure suppression and postictal sleep. Experimental neurology. 2014; 253:82-90. [PubMed: 24333565]

43. Akarsu ES, et al. Inhibition of pentylenetetrazol-induced seizures in rats by prostaglandin D2. Epilepsy Res. 1998; 30:63-68. [PubMed: 9551845]

44. Chung JI, et al. Seizure susceptibility in immature brain due to lack of COX-2-induced PGF2alpha. Experimental neurology. 2013; 249:95-103. [PubMed: 24005111]

45. Shimamura M, et al. Prostaglandin E2 type 1 receptors contribute to neuronal apoptosis after transient forebrain ischemia. Journal of cerebral blood flow and metabolism : official journal of the International Society of Cerebral Blood Flow and Metabolism. 2013; 33:1207-1214.

46. Zhou P, et al. Neuroprotection by PGE2 receptor EP1 inhibition involves the PTEN/AKT pathway. Neurobiol Dis. 2008; 29:543-551. [PubMed: 18178094]

47. Kawano T, et al. Prostaglandin E2 EP1 receptors: downstream effectors of COX-2 neurotoxicity. Nature medicine. 2006; 12:225-229.

48. Zhen G, et al. PGE2 EP1 receptor exacerbated neurotoxicity in a mouse model of cerebral ischemia and Alzheimer's disease. Neurobiol Aging. 2012; 33:2215-2219. [PubMed: 22015313]

49. Frankowski JC, et al. Detrimental role of the EP1 prostanoid receptor in blood-brain barrier damage following experimental ischemic stroke. Scientific reports. 2015; 5:17956. [PubMed: 26648273]

50. Rojas A, et al. The prostaglandin EP1 receptor potentiates kainate receptor activation via a protein kinase C pathway and exacerbates status epilepticus. Neurobiol Dis. 2014; 70:74-89. [PubMed: 24952362]

51. Pekcec A, et al. Targeting prostaglandin E2 EP1 receptors prevents seizure-associated Pglycoprotein up-regulation. The Journal of pharmacology and experimental therapeutics. 2009; 330:939-947. [PubMed: 19494186]

52. Jiang J, Dingledine R. Prostaglandin receptor EP2 in the crosshairs of anti-inflammation, anticancer, and neuroprotection. Trends in pharmacological sciences. 2013; 34:413-423. [PubMed: 23796953]

53. Quan Y, et al. EP2 receptor signaling pathways regulate classical activation of microglia. The Journal of biological chemistry. 2013; 288:9293-9302. [PubMed: 23404506]

54. Fu Y, et al. EP2 Receptor Signaling Regulates Microglia Death. Molecular pharmacology. 2015; 88:161-170. [PubMed: 25715797]

55. Jiang, J., et al. Prostaglandin receptor EP2 antagonists, derivatives, compositions, and uses related thereto. US. 20140179750A1.

56. Jiang J, et al. Small molecule antagonist reveals seizure-induced mediation of neuronal injury by prostaglandin E2 receptor subtype EP2. Proceedings of the National Academy of Sciences of the United States of America. 2012; 109:3149-3154. [PubMed: 22323596]

57. Jiang J, Dingledine R. Role of prostaglandin receptor EP2 in the regulations of cancer cell proliferation, invasion, and inflammation. The Journal of pharmacology and experimental therapeutics. 2013; 344:360-367. [PubMed: 23192657]

58. Hagmann WK. The many roles for fluorine in medicinal chemistry. Journal of medicinal chemistry. 2008; 51:4359-4369. [PubMed: 18570365]

59. Jiang $\mathrm{J}$, et al. Inhibition of the prostaglandin receptor EP2 following status epilepticus reduces delayed mortality and brain inflammation. Proceedings of the National Academy of Sciences of the United States of America. 2013; 110:3591-3596. [PubMed: 23401547]

60. Rojas A, et al. Inhibition of the prostaglandin EP2 receptor is neuroprotective and accelerates functional recovery in a rat model of organophosphorus induced status epilepticus. Neuropharmacology. 2015; 93:15-27. [PubMed: 25656476]

61. Ganesh T, et al. Discovery and characterization of carbamothioylacrylamides as EP selective antagonists. ACS medicinal chemistry letters. 2013; 4:616-621. [PubMed: 23914286]

62. Ganesh T, et al. Lead optimization studies of cinnamic amide EP2 antagonists. Journal of medicinal chemistry. 2014; 57:4173-4184. [PubMed: 24773616] 
63. Ganesh T, et al. Development of second generation EP2 antagonists with high selectivity. European journal of medicinal chemistry. 2014; 82:521-535. [PubMed: 24937185]

64. Kim YT, et al. Prostaglandin FP receptor inhibitor reduces ischemic brain damage and neurotoxicity. Neurobiol Dis. 2012; 48:58-65. [PubMed: 22709986]

65. Shi J, et al. Inflammatory prostaglandin E2 signaling in a mouse model of Alzheimer disease. Annals of neurology. 2012; 72:788-798. [PubMed: 22915243]

66. Ni H, et al. EP3, Prostaglandin E2 Receptor Subtype 3, Associated with Neuronal Apoptosis Following Intracerebral Hemorrhage. Cell Mol Neurobiol. 2015:1-10.

67. Ravizza T, Vezzani A. Status epilepticus induces time-dependent neuronal and astrocytic expression of interleukin-1 receptor type I in the rat limbic system. Neuroscience. 2006; 137:301308. [PubMed: 16289587]

68. Ravizza T, et al. Innate and adaptive immunity during epileptogenesis and spontaneous seizures: evidence from experimental models and human temporal lobe epilepsy. Neurobiol Dis. 2008; 29:142-160. [PubMed: 17931873]

69. Boer K, et al. Inflammatory processes in cortical tubers and subependymal giant cell tumors of tuberous sclerosis complex. Epilepsy Res. 2008; 78:7-21. [PubMed: 18023148]

70. Henshall DC, et al. Alterations in bcl-2 and caspase gene family protein expression in human temporal lobe epilepsy. Neurology. 2000; 55:250-257. [PubMed: 10908900]

71. Hu S, et al. Cytokine effects on glutamate uptake by human astrocytes. Neuroimmunomodulation. 2000; 7:153-159. [PubMed: 10754403]

72. Viviani B, et al. Interleukin-1beta enhances NMDA receptor-mediated intracellular calcium increase through activation of the Src family of kinases. The Journal of neuroscience : the official journal of the Society for Neuroscience. 2003; 23:8692-8700. [PubMed: 14507968]

73. Roseti C, et al. GABAA currents are decreased by IL-1beta in epileptogenic tissue of patients with temporal lobe epilepsy: implications for ictogenesis. Neurobiol Dis. 2015; 82:311-320. [PubMed: 26168875]

74. Vezzani A, Viviani B. Neuromodulatory properties of inflammatory cytokines and their impact on neuronal excitability. Neuropharmacology. 2015; 96:70-82. [PubMed: 25445483]

75. Lamkanfi M, et al. Inflammasome-dependent release of the alarmin HMGB1 in endotoxemia. Journal of immunology. 2010; 185:4385-4392.

76. Maroso M, et al. Toll-like receptor 4 and high-mobility group box-1 are involved in ictogenesis and can be targeted to reduce seizures. Nature medicine. 2010; 16:413-419.

77. Iori V, et al. Receptor for Advanced Glycation Endproducts is upregulated in temporal lobe epilepsy and contributes to experimental seizures. Neurobiol Dis. 2013; 58:102-114. [PubMed: 23523633]

78. Balosso S, et al. Disulfide-containing high mobility group box-1 promotes N-methyl-D-aspartate receptor function and excitotoxicity by activating Toll-like receptor 4-dependent signaling in hippocampal neurons. Antioxid Redox Signal. 2014; 21:1726-1740. [PubMed: 24094148]

79. Vezzani A, et al. Powerful anticonvulsant action of IL-1 receptor antagonist on intracerebral injection and astrocytic overexpression in mice. Proceedings of the National Academy of Sciences of the United States of America. 2000; 97:11534-11539. [PubMed: 11016948]

80. Vezzani A, et al. Functional role of inflammatory cytokines and antiinflammatory molecules in seizures and epileptogenesis. Epilepsia. 2002; 43(Suppl 5):30-35. [PubMed: 12121291]

81. Marchi N, et al. Antagonism of peripheral inflammation reduces the severity of status epilepticus. Neurobiol Dis. 2009; 33:171-181. [PubMed: 19010416]

82. Auvin S, et al. Inflammation induced by LPS enhances epileptogenesis in immature rat and may be partially reversed by IL1RA. Epilepsia. 2010; 51(Suppl 3):34-38. [PubMed: 20618397]

83. Braddock M, Quinn A. Targeting IL-1 in inflammatory disease: new opportunities for therapeutic intervention. Nat Rev Drug Discov. 2004; 3:330-339. [PubMed: 15060528]

84. Rudolphi K, et al. Pralnacasan, an inhibitor of interleukin-1beta converting enzyme, reduces joint damage in two murine models of osteoarthritis. Osteoarthritis and cartilage /OARS, Osteoarthritis Research Society. 2003; 11:738-746. 
85. Loher F, et al. The interleukin-1 beta-converting enzyme inhibitor pralnacasan reduces dextran sulfate sodium-induced murine colitis and T helper $1 \mathrm{~T}$-cell activation. The Journal of pharmacology and experimental therapeutics. 2004; 308:583-590. [PubMed: 14610233]

86. Wannamaker W, et al. (S)-1-((S)-2-\{[1-(4-amino-3-chloro-phenyl)-methanoyl]-amino\}-3,3dimethyl-butanoy 1)-pyrrolidine-2-carboxylic acid ((2R,3S)-2-ethoxy-5-oxo-tetrahydro-furan-3yl)-amide (VX-765), an orally available selective interleukin (IL)-converting enzyme/caspase-1 inhibitor, exhibits potent anti-inflammatory activities by inhibiting the release of IL-1beta and IL-18. The Journal of pharmacology and experimental therapeutics. 2007; 321:509-516. [PubMed: 17289835]

87. Zhang Y, et al. NLRP3 Inflammasome Mediates Chronic Mild Stress-Induced Depression in Mice via Neuroinflammation. Int J Neuropsychopharmacol. 2015:18.

88. Ravizza T, et al. Inactivation of caspase-1 in rodent brain: a novel anticonvulsive strategy. Epilepsia. 2006; 47:1160-1168. [PubMed: 16886979]

89. Ravizza T, et al. Interleukin Converting Enzyme inhibition impairs kindling epileptogenesis in rats by blocking astrocytic IL-1beta production. Neurobiol Dis. 2008; 31:327-333. [PubMed: 18632279]

90. Maroso M, et al. Interleukin-1beta biosynthesis inhibition reduces acute seizures and drug resistant chronic epileptic activity in mice. Neurotherapeutics: the journal of the American Society for Experimental NeuroTherapeutics. 2011; 8:304-315. [PubMed: 21431948]

91. Yingling JM, et al. Development of TGF-beta signalling inhibitors for cancer therapy. Nat Rev Drug Discov. 2004; 3:1011-1022. [PubMed: 15573100]

92. Yu L, et al. TGF-beta receptor-activated p38 MAP kinase mediates Smad-independent TGF-beta responses. The EMBO journal. 2002; 21:3749-3759. [PubMed: 12110587]

93. He Y, et al. ALK5-dependent TGF-beta signaling is a major determinant of late-stage adult neurogenesis. Nature neuroscience. 2014; 17:943-952. [PubMed: 24859199]

94. Cacheaux LP, et al. Transcriptome profiling reveals TGF-beta signaling involvement in epileptogenesis. The Journal of neuroscience : the official journal of the Society for Neuroscience. 2009; 29:8927-8935. [PubMed: 19605630]

95. van Vliet EA, et al. Blood-brain barrier leakage may lead to progression of temporal lobe epilepsy. Brain. 2007; 130:521-534. [PubMed: 17124188]

96. Ivens $\mathrm{S}$, et al. TGF-beta receptor-mediated albumin uptake into astrocytes is involved in neocortical epileptogenesis. Brain. 2007; 130:535-547. [PubMed: 17121744]

97. Friedman A, et al. Blood-brain barrier breakdown-inducing astrocytic transformation: novel targets for the prevention of epilepsy. Epilepsy Res. 2009; 85:142-149. [PubMed: 19362806]

98. Heinemann U, et al. Blood-brain barrier dysfunction, TGFbeta signaling, and astrocyte dysfunction in epilepsy. Glia. 2012; 60:1251-1257. [PubMed: 22378298]

99. Weissberg I, et al. Albumin induces excitatory synaptogenesis through astrocytic TGF-beta/ALK5 signaling in a model of acquired epilepsy following blood-brain barrier dysfunction. Neurobiol Dis. 2015; 78:115-125. [PubMed: 25836421]

100. Bar-Klein G, et al. Losartan prevents acquired epilepsy via TGF-beta signaling suppression. Annals of neurology. 2014; 75:864-875. [PubMed: 24659129]

101. Uttara B, et al. Oxidative stress and neurodegenerative diseases: a review of upstream and downstream antioxidant therapeutic options. Curr Neuropharmacol. 2009; 7:65-74. [PubMed: 19721819]

102. Panday A, et al. NADPH oxidases: an overview from structure to innate immunity-associated pathologies. Cell Mol Immunol. 2015; 12:5-23. [PubMed: 25263488]

103. Bedard K, Krause KH. The NOX family of ROS-generating NADPH oxidases: physiology and pathophysiology. Physiol Rev. 2007; 87:245-313. [PubMed: 17237347]

104. Khayrullina G, et al. Inhibition of NOX2 reduces locomotor impairment, inflammation, and oxidative stress after spinal cord injury. J Neuroinflammation. 2015; 12:172. [PubMed: 26377802]

105. Wang Q, et al. Post-treatment with an ultra-low dose of NADPH oxidase inhibitor diphenyleneiodonium attenuates disease progression in multiple Parkinson's disease models. Brain. 2015; 138:1247-1262. [PubMed: 25716193] 
106. Chen $\mathrm{SH}$, et al. Critical role of the Mac1/NOX2 pathway in mediating reactive microgliosisgenerated chronic neuroinflammation and progressive neurodegeneration. Curr Opin Pharmacol. 2016; 26:54-60. [PubMed: 26498406]

107. Wilkinson BL, et al. Ibuprofen attenuates oxidative damage through NOX2 inhibition in Alzheimer's disease. Neurobiol Aging. 2012; 33:197 e121-132.

108. Apolloni S, et al. The NADPH oxidase pathway is dysregulated by the P2X7 receptor in the SOD1-G93A microglia model of amyotrophic lateral sclerosis. Journal of immunology. 2013; 190:5187-5195.

109. Fischer MT, et al. NADPH oxidase expression in active multiple sclerosis lesions in relation to oxidative tissue damage and mitochondrial injury. Brain. 2012; 135:886-899. [PubMed: 22366799]

110. Puttachary S, et al. Seizure-induced oxidative stress in temporal lobe epilepsy. Biomed Res Int. 2015; 2015:745613. [PubMed: 25650148]

111. Freitas RM, et al. Oxidative stress in the hippocampus after pilocarpine-induced status epilepticus in Wistar rats. FEBS J. 2005; 272:1307-1312. [PubMed: 15752349]

112. Patel M, et al. Activation of NADPH oxidase and extracellular superoxide production in seizureinduced hippocampal damage. Journal of neurochemistry. 2005; 92:123-131. [PubMed: 15606902]

113. Pestana RR, et al. Reactive oxygen species generated by NADPH oxidase are involved in neurodegeneration in the pilocarpine model of temporal lobe epilepsy. Neuroscience letters. 2010; 484:187-191. [PubMed: 20732386]

114. Kim JH, et al. Post-treatment of an NADPH oxidase inhibitor prevents seizure-induced neuronal death. Brain research. 2013; 1499:163-172. [PubMed: 23313582]

115. Altenhofer S, et al. Evolution of NADPH Oxidase Inhibitors: Selectivity and Mechanisms for Target Engagement. Antioxid Redox Signal. 2015; 23:406-427. [PubMed: 24383718]

116. Maraldi T. Natural compounds as modulators of NADPH oxidases. Oxidative medicine and cellular longevity. 2013; 2013:271602. [PubMed: 24381714]

117. Hirano K, et al. Discovery of GSK2795039, a Novel Small Molecule NADPH Oxidase 2 Inhibitor. Antioxid Redox Signal. 2015; 23:358-374. [PubMed: 26135714]

118. Leone $S$, et al. Dual acting anti-inflammatory drugs. Current topics in medicinal chemistry. 2007; 7:265-275. [PubMed: 17305569]

119. Minutoli L, et al. A dual inhibitor of cyclooxygenase and 5-lipoxygenase protects against kainic acid-induced brain injury. Neuromolecular medicine. 2015; 17:192-201. [PubMed: 25893744]

120. Payandemehr B, et al. A COX/5-LOX Inhibitor Licofelone Revealed Anticonvulsant Properties Through iNOS Diminution in Mice. Neurochem Res. 2015; 40:1819-1828. [PubMed: 26216049]

121. Trebino CE, et al. Impaired inflammatory and pain responses in mice lacking an inducible prostaglandin E synthase. Proceedings of the National Academy of Sciences of the United States of America. 2003; 100:9044-9049. [PubMed: 12835414]

122. Chaudhry UA, et al. Elevated microsomal prostaglandin-E synthase-1 in Alzheimer's disease. Alzheimer's \& dementia : the journal of the Alzheimer's Association. 2008; 4:6-13.

123. Akitake Y, et al. Microsomal prostaglandin E synthase-1 is induced in alzheimer's disease and its deletion mitigates alzheimer's disease-like pathology in a mouse model. Journal of neuroscience research. 2013; 91:909-919. [PubMed: 23553915]

124. Koeberle A, Werz O. Perspective of microsomal prostaglandin E2 synthase-1 as drug target in inflammation-related disorders. Biochemical pharmacology. 2015; 98:1-15. [PubMed: 26123522]

125. Takeuchi $\mathrm{C}$, et al. Microsomal prostaglandin E synthase-1 aggravates inflammation and demyelination in a mouse model of multiple sclerosis. Neurochemistry international. 2013; 62:271-280. [PubMed: 23266396]

126. Turrin NP, Rivest S. Innate immune reaction in response to seizures: implications for the neuropathology associated with epilepsy. Neurobiol Dis. 2004; 16:321-334. [PubMed: 15193289]

127. Takemiya T, et al. Endothelial microsomal prostaglandin E synthase-1 exacerbates neuronal loss induced by kainate. Journal of neuroscience research. 2010; 88:381-390. [PubMed: 19658194] 
128. Shimada T, et al. Role of inflammatory mediators in the pathogenesis of epilepsy. Mediators of inflammation. 2014; 2014:901902. [PubMed: 25197169]

129. Jin Y, et al. Pharmacodynamic comparison of LY3023703, a novel microsomal prostaglandin e synthase 1 inhibitor, with celecoxib. Clinical pharmacology and therapeutics. 2016; 99:274-284. [PubMed: 26351780]

130. Koeberle A, et al. Design and Development of Microsomal Prostaglandin E Synthase-1 Inhibitors: Challenges and Future Directions. Journal of medicinal chemistry. 2016

131. Bowie A, O'Neill LA. The interleukin-1 receptor/Toll-like receptor superfamily: signal generators for pro-inflammatory interleukins and microbial products. Journal of leukocyte biology. 2000; 67:508-514. [PubMed: 10770283]

132. Walker A, et al. Proteomic profiling of epileptogenesis in a rat model: Focus on inflammation. Brain, behavior, and immunity. 2015

133. Moses T, et al. TLR4-mediated Cox-2 expression increases intestinal ischemia/reperfusioninduced damage. Journal of leukocyte biology. 2009; 86:971-980. [PubMed: 19564573]

134. Fukata M, et al. Cox-2 is regulated by Toll-like receptor-4 (TLR4) signaling: Role in proliferation and apoptosis in the intestine. Gastroenterology. 2006; 131:862-877. [PubMed: 16952555]

135. Kuper C, et al. Toll-like receptor 4 activates NF-kappaB and MAP kinase pathways to regulate expression of proinflammatory COX-2 in renal medullary collecting duct cells. American journal of physiology Renal physiology. 2012; 302:F38-46. [PubMed: 21937604]

136. Vezzani A, et al. IL-1 receptor/Toll-like receptor signaling in infection, inflammation, stress and neurodegeneration couples hyperexcitability and seizures. Brain, behavior, and immunity. 2011; 25:1281-1289.

137. Sonar S, Lal G. Role of Tumor Necrosis Factor Superfamily in Neuroinflammation and Autoimmunity. Frontiers in immunology. 2015; 6:364. [PubMed: 26257732]

138. Shandra AA, et al. The role of TNF-alpha in amygdala kindled rats. Neuroscience research. 2002; 42:147-153. [PubMed: 11849734]

139. Balosso $\mathrm{S}$, et al. Tumor necrosis factor-alpha inhibits seizures in mice via p75 receptors. Annals of neurology. 2005; 57:804-812. [PubMed: 15852477]

140. Weinberg MS, et al. Opposing actions of hippocampus TNFalpha receptors on limbic seizure susceptibility. Experimental neurology. 2013; 247:429-437. [PubMed: 23333565]

141. Balosso S, et al. Molecular and functional interactions between tumor necrosis factor-alpha receptors and the glutamatergic system in the mouse hippocampus: implications for seizure susceptibility. Neuroscience. 2009; 161:293-300. [PubMed: 19285115]

142. Balosso S, et al. The dual role of TNF-alpha and its receptors in seizures. Experimental neurology. 2013; 247:267-271. [PubMed: 23707217]

143. Kitagaki M, et al. Novel TNF-alpha receptor 1 antagonist treatment attenuates arterial inflammation and intimal hyperplasia in mice. Journal of atherosclerosis and thrombosis. 2012; 19:36-46. [PubMed: 22146239]

144. Fischer R, et al. A TNF receptor 2 selective agonist rescues human neurons from oxidative stressinduced cell death. PloS one. 2011; 6:e27621. [PubMed: 22110694]

145. Nakao S, et al. Tumor necrosis factor alpha (TNF-alpha)-induced prostaglandin E2 release is mediated by the activation of cyclooxygenase-2 (COX-2) transcription via NFkappaB in human gingival fibroblasts. Molecular and cellular biochemistry. 2002; 238:11-18. [PubMed: 12349897]

146. Medeiros R, et al. The role of TNF-alpha signaling pathway on COX-2 upregulation and cognitive decline induced by beta-amyloid peptide. Behavioural brain research. 2010; 209:165173. [PubMed: 20122965]

147. Chikuma $\mathrm{T}$, et al. Interleukin-6 induces prostaglandin $\mathrm{E}(2)$ synthesis in mouse astrocytes. Journal of molecular neuroscience : MN. 2009; 39:175-184. [PubMed: 19277492]

148. Li G, et al. Cytokines and epilepsy. Seizure. 2011; 20:249-256. [PubMed: 21216630]

149. Vezzani A, et al. The role of cytokines in the pathophysiology of epilepsy. Brain, behavior, and immunity. 2008; 22:797-803.

150. Kalueff AV, et al. Intranasal administration of human IL-6 increases the severity of chemically induced seizures in rats. Neuroscience letters. 2004; 365:106-110. [PubMed: 15245788] 
151. De Luca G, et al. Susceptibility to audiogenic seizure and neurotransmitter amino acid levels in different brain areas of IL-6-deficient mice. Pharmacology, biochemistry, and behavior. 2004; 78:75-81.

152. Penkowa M, et al. Interleukin-6 deficiency reduces the brain inflammatory response and increases oxidative stress and neurodegeneration after kainic acid-induced seizures. Neuroscience. 2001; 102:805-818. [PubMed: 11182244]

153. Samland H, et al. Profound increase in sensitivity to glutamatergic- but not cholinergic agonistinduced seizures in transgenic mice with astrocyte production of IL-6. Journal of neuroscience research. 2003; 73:176-187. [PubMed: 12836160]

154. Quek AL, et al. Autoimmune epilepsy: Clinical characteristics and response to immunotherapy. Archives of neurology. 2012; 69:582-593. [PubMed: 22451162]

155. Vincent A, et al. The growing recognition of immunotherapy-responsive seizure disorders with autoantibodies to specific neuronal proteins. Current opinion in neurology. 2010; 23:144-150. [PubMed: 20164770]

156. Laflamme N, et al. An essential role of interleukin-1beta in mediating NF-kappaB activity and $\mathrm{COX}-2$ transcription in cells of the blood-brain barrier in response to a systemic and localized inflammation but not during endotoxemia. The Journal of neuroscience : the official journal of the Society for Neuroscience. 1999; 19:10923-10930. [PubMed: 10594073]

157. Strengell T, et al. Antipyretic agents for preventing recurrences of febrile seizures: randomized controlled trial. Archives of Pediatrics \& Adolescent Medicine. 2009; 163:799-804. [PubMed: 19736332]

158. Bialer M, et al. Progress report on new antiepileptic drugs: a summary of the Eleventh Eilat Conference (EILAT XI). Epilepsy Res. 2013; 103:2-30. [PubMed: 23219031]

159. French J, et al. AES 2013 Annual Meeting - Online Abstract Supplement. Epilepsy Currents. 2014; $14: 1-475$.

160. Noe FM, et al. Pharmacological blockade of IL-1beta/IL-1 receptor type 1 axis during epileptogenesis provides neuroprotection in two rat models of temporal lobe epilepsy. Neurobiol Dis. 2013; 59:183-193. [PubMed: 23938763]

161. Kwon YS, et al. Neuroprotective and antiepileptogenic effects of combination of antiinflammatory drugs in the immature brain. J Neuroinflammation. 2013; 10:30. [PubMed: 23442201]

162. Yang CY. Identification of potential small molecule allosteric modulator sites on IL-1R1 ectodomain using accelerated conformational sampling method. PloS one. 2015; 10:e0118671. [PubMed: 25706624]

163. Janigro D. Are you in or out? Leukocyte, ion, and neurotransmitter permeability across the epileptic blood-brain barrier. Epilepsia. 2012; 53(Suppl 1):26-34.

164. Marchi N, et al. Seizure-promoting effect of blood-brain barrier disruption. Epilepsia. 2007; 48:732-742. [PubMed: 17319915]

165. Zattoni M, et al. Brain infiltration of leukocytes contributes to the pathophysiology of temporal lobe epilepsy. The Journal of neuroscience : the official journal of the Society for Neuroscience. 2011; 31:4037-4050. [PubMed: 21411646]

166. Gorter JA, et al. Status epilepticus, blood-brain barrier disruption, inflammation, and epileptogenesis. Epilepsy \& behavior : E\&B. 2015; 49:13-16.

167. Levite M. Autoimmune epilepsy. Nature immunology. 2002; 3:500. [PubMed: 12032558]

168. Bien CG, et al. Limbic encephalitis as a precipitating event in adult-onset temporal lobe epilepsy. Neurology. 2007; 69:1236-1244. [PubMed: 17875912]

169. Vezzani A, et al. Infections, inflammation and epilepsy. Acta neuropathologica. 2016; 131:211234. [PubMed: 26423537]

170. Dube $\mathrm{C}$, et al. Interleukin-1beta contributes to the generation of experimental febrile seizures. Annals of neurology. 2005; 57:152-155. [PubMed: 15622539]

171. Kovacs Z, et al. Facilitation of spike-wave discharge activity by lipopolysaccharides in Wistar Albino Glaxo/Rijswijk rats. Neuroscience. 2006; 140:731-742. [PubMed: 16616432]

172. Auvin S, et al. Inflammation enhances epileptogenesis in the developing rat brain. Neurobiol Dis. 2010; 40:303-310. [PubMed: 20600912] 


\section{TRENDS}

Unresolved inflammation in the brain is a common feature in epilepsy, and is primarily characterized by elevated proinflammatory mediators in epileptogenic foci.

Blocking excessive inflammatory processes in the brain increases the seizure threshold and reduces the likelihood of recurrent seizures, thereby providing disease prevention or modification.

Anti-inflammatory therapeutics represent a complementary strategy to the current symptomatic treatments.

Small molecules that specifically target the proinflammatory mediators are realistic candidate agents for anti-inflammatory therapeutics owing to their advantages in production, delivery and pharmacokinetics. 


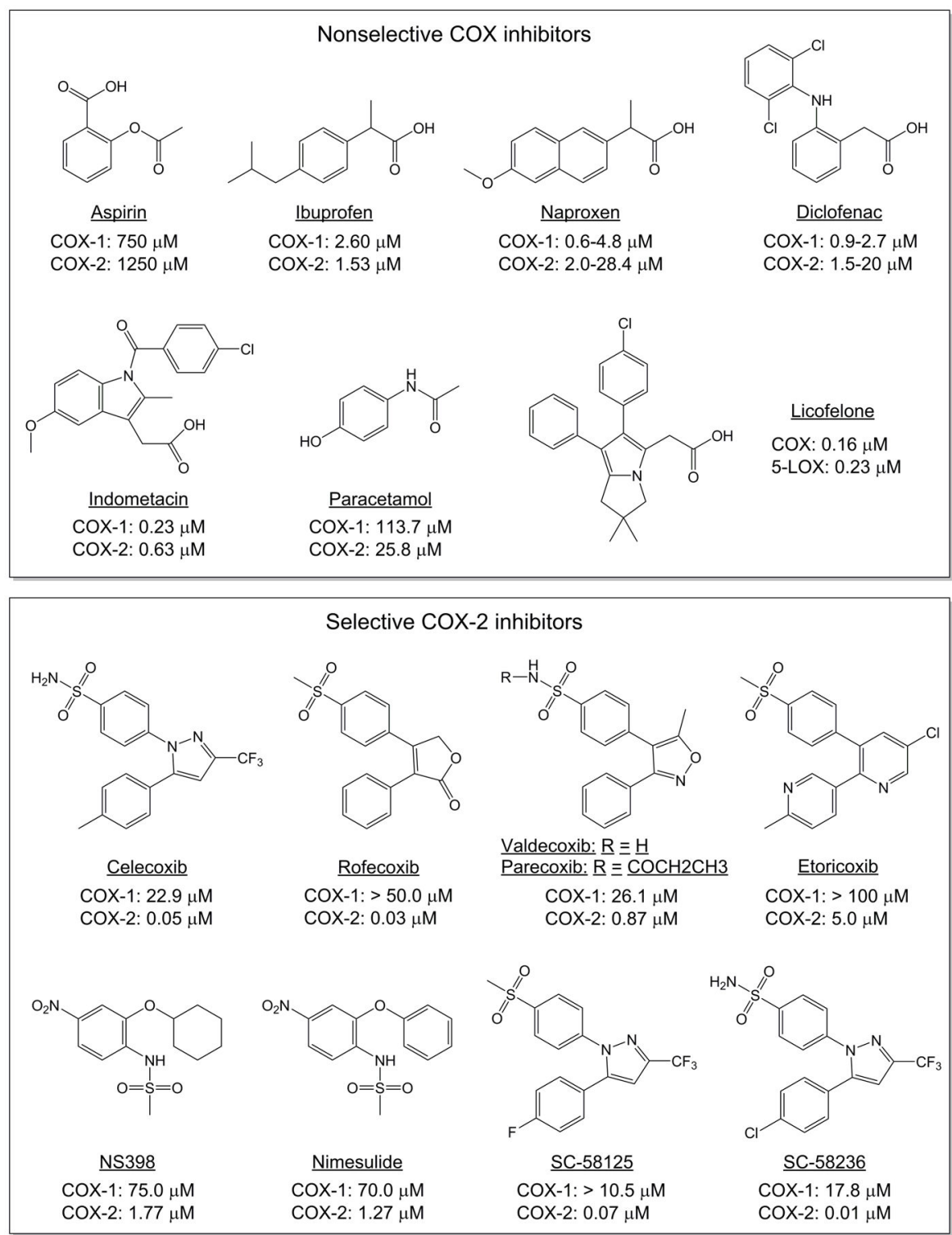

Figure 1.

Chemical structures of small molecules that inhibit COX and have been tested in animal models for antiepileptic and antiepileptogenic effects. The $\mathrm{IC}_{50} \mathrm{~s}$ on $\mathrm{COX}-1$ and $\mathrm{COX}-2$ of each compound are indicated. Note that licofelone is a dual COX/LOX inhibitor and parecoxib is a pro-drug of valdecoxib. 


\section{A}

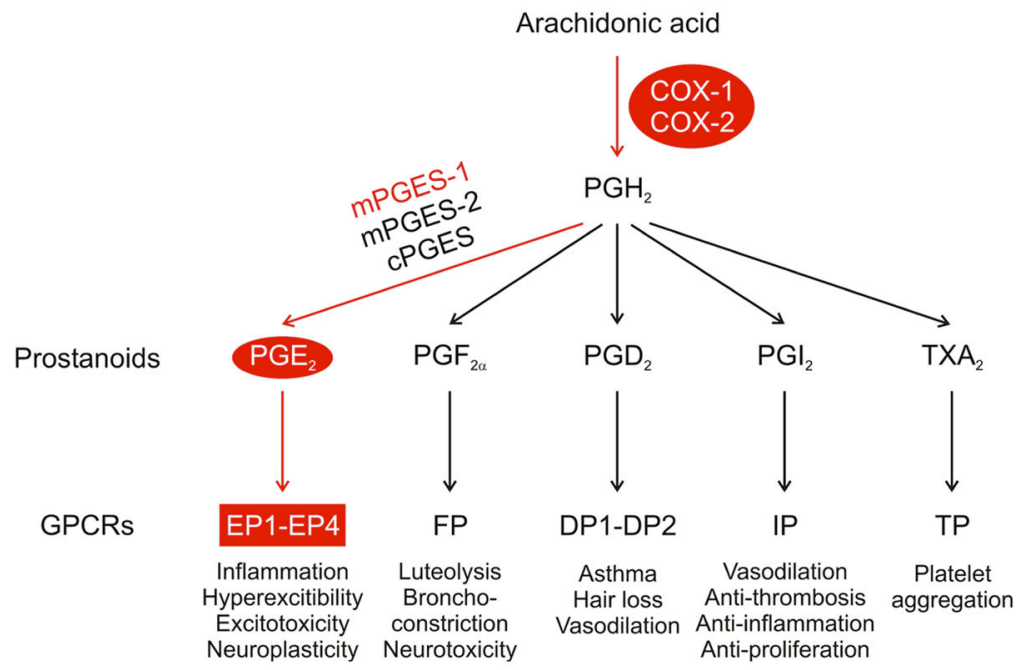

B

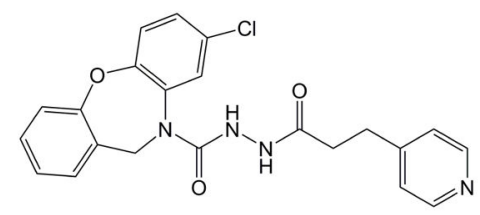

$\underline{\text { SC-51089 }}$

EP1 $K_{\mathrm{i}}: 1332 \mathrm{nM}$

Selectivity: at least 8.4-fold against

other prostanoid receptors

C

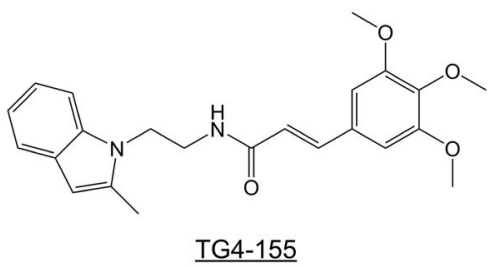

EP2 $K_{\mathrm{B}}: 2.4 \mathrm{nM}$

Selectivity: 14 - to 4,730 -fold against

other prostanoid receptors

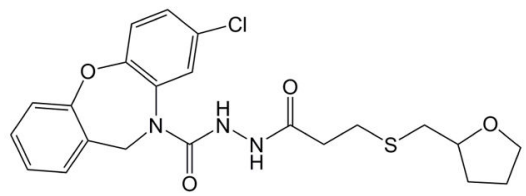

$\underline{\text { SC-51322 }}$

EP1 $K_{\mathrm{i}}: 13.8 \mathrm{nM}$

Selectivity: at least 37 -fold against other prostanoid receptors

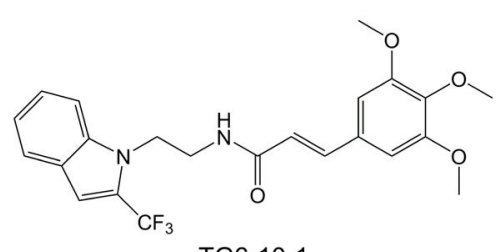

EP2 $K_{\mathrm{B}}: 17.8 \mathrm{nM}$

Selectivity: 10- to 970 -fold against other prostanoid receptors

Figure 2.

COX-2 and inflammatory prostaglandin signaling pathways. (A) COX cascade mediates a variety of physiological and pathological events via its prostanoid products. In response to disparate stimuli, the membrane-bound arachidonic acid is freed and converted to unstable intermediate $\mathrm{PGH}_{2}$ by $\mathrm{COX}$, which has two forms: constitutive COX-1 and inducible COX-2. Short-lived $\mathrm{PGH}_{2}$ is then quickly converted to five prostanoids, consisting of prostaglandin $\mathrm{PGD}_{2}, \mathrm{PGE}_{2}, \mathrm{PGF}_{2 a}$, prostacyclin $\mathrm{PGI}_{2}$, and thromboxane $\mathrm{TXA}_{2}$, by tissuespecific prostanoid synthases. Prostanoids exert their functions via activating a suite of GPCRs. Four receptors - EP1, EP2, EP3 and EP4 - are activated by $\mathrm{PGE}_{2}$, and two by $\mathrm{PGE}_{2}$ 
(DP1 and DP2), whereas each of the other three prostanoids activates a single receptor (FP, IP, TP). The inflammatory prostaglandin signaling is mainly mediated by $\mathrm{PGE}_{2}$ and its receptors. Only the major pathways are shown. (B) Chemical structures of example small molecules that selectively block prostaglandin $\mathrm{PGE}_{2}$ receptor subtype EP2. The potency (Schild $K_{\mathrm{B}}$ ) and selectivity of each compound are indicated. (C) Chemical structures of small molecules that selectively block EP1 receptor. The potency $(K \mathbf{i})$ and selectivity of each compound are indicated. Abbreviations: COX, cyclooxygenase; GPCRs, G protein-coupled receptors; PG, prostaglandin; PGES, prostaglandin E synthase. 


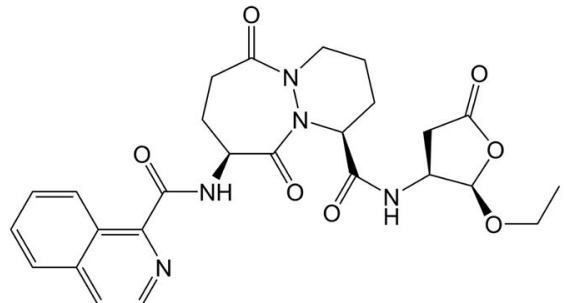

$\underline{\mathrm{VX}-740}$

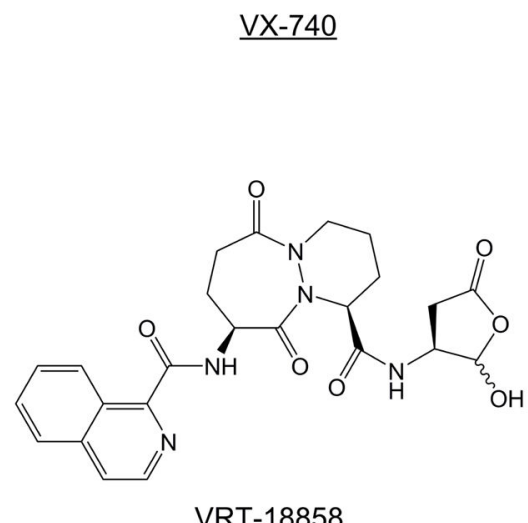

VRT-18858

Caspase-1 $K_{\mathrm{i}}: 1.3 \mathrm{nM}$ Caspase-3 $K_{\mathrm{i}}: 2,300 \mathrm{nM}$ Caspase-8 $K_{\mathrm{i}}: 120 \mathrm{nM}$<smiles>CCO[C@@H]1OC(=O)C[C@H]1NC(=O)[C@@H]1CCCN1C(=O)[C@@H](NC(=O)c1ccc(N)c(Cl)c1)C(C)(C)C</smiles>

\section{$\underline{V X-765}$}

Esterases<smiles>CC(C)(C)[C@H](NC(=O)c1ccc(N)c(Cl)c1)C(=O)N1CCC[C@H]1C(=O)N[C@H]1CC(=O)O[C@@H]1O</smiles>

\section{$\underline{\text { VRT-043198 }}$}

Caspase-1 $K_{\mathrm{i}}: 0.8 \mathrm{nM} \quad$ Caspase-7 $K_{\mathrm{i}}: 16,000 \mathrm{nM}$ Caspase-3 $K_{\mathrm{i}}: 21,500 \mathrm{nM}$ Caspase-8 $K_{\mathrm{i}}: 100 \mathrm{nM}$ Caspase- $4 K_{\mathrm{i}}:<0.6 \mathrm{nM}$ Caspase- $9 K_{\mathrm{i}}: 1030 \mathrm{nM}$ Caspase- $6 K_{\mathrm{i}}: 560 \mathrm{nM}$

Figure 3.

Chemical structures of caspase-1 inhibitors and pro-drugs. VX-740 and VX-765 are rapidly converted to VRT-18858 and VRT-043198, respectively, by plasma and liver esterases in vivo. The $K_{\mathrm{i}} \mathrm{s}$ of each compound on caspase- 1 and other caspases are indicated. 
<smiles>Cc1cccc(-c2n[nH]cc2-c2ccc3ncccc3n2)n1</smiles>

SJN2511 (RepSox)

ALK5 IC 50 : 4-23 nM

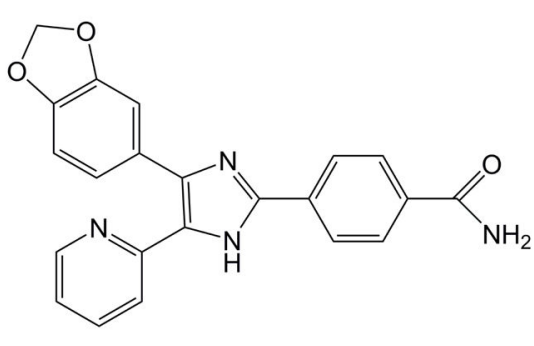

SB431542

ALK5 IC $50: 94 \mathrm{nM}$

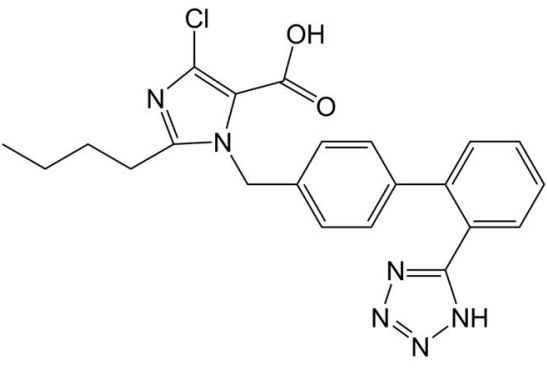

Losartan

$\mathrm{AT}_{1} \mathrm{IC}_{50}: 5-20 \mathrm{nM}$

Figure 4.

Chemical structures of small molecules that suppress TGF- $\beta 1 /$ ALK5 signaling. SJN2511 and SB431542 are selective ALK5 inhibitors. Losartan, a selective antagonist for AT1 can downregulate TGF- $\beta$ /ALK5 signaling in both the periphery and the CNS. Abbreviations: ALK5, activin-like kinase 5; AT1, angiotensin II receptor type 1. 
<smiles>COc1cc(C(C)=O)ccc1O</smiles>

Apocynin

NOX $1 C_{50}: 10 \mu \mathrm{M}$

XO IC $50: 91 \mu \mathrm{M}$<smiles>Cl[c-]1c2ccccc2c2ccccc21</smiles>

Diphenyleneiodonium

NOX $K_{\mathrm{i}}: 5.6 \mu \mathrm{M}$

iNOS IC $50: 50 \mathrm{nM}$ eNOS IC $50: 0.3 \mu \mathrm{M}$

$\mathrm{XO} \mathrm{IC}_{50}: 0.3 \mu \mathrm{M}$<smiles>CC(C)n1cc(-c2ccc3c(c2)N(C)CC3)c2c(NS(=O)(=O)c3ccn(C)n3)ccnc21</smiles>

GSK2795039

NOX1 IC $50:>100 \mu \mathrm{M}$

NOX2 IC ${ }_{50}: 2.9 \mu \mathrm{M}$

NOX3 IC $50:>100 \mu \mathrm{M}$

NOX4 $\mathrm{IC}_{50}:>100 \mu \mathrm{M}$

NOX5 $\mathrm{IC}_{50}:>100 \mu \mathrm{M}$

eNOS IC $50:>100 \mu \mathrm{M}$

$\mathrm{XO} \mathrm{IC}_{50}: 28.8 \mu \mathrm{M}$

Figure 5.

Chemical structures of classical NOX inhibitors apocynin and diphenyleneiodonium. Note that both compounds have considerable off-target inhibitions. Recently developed compounds like GSK2795039 with improved selectivity await to be tested in animal models of seizures and epilepsy. Abbreviations: eNOS, endothelial nitric oxide synthase (NOS); iNOS, inducible NOS; XO, xanthine oxidase. 


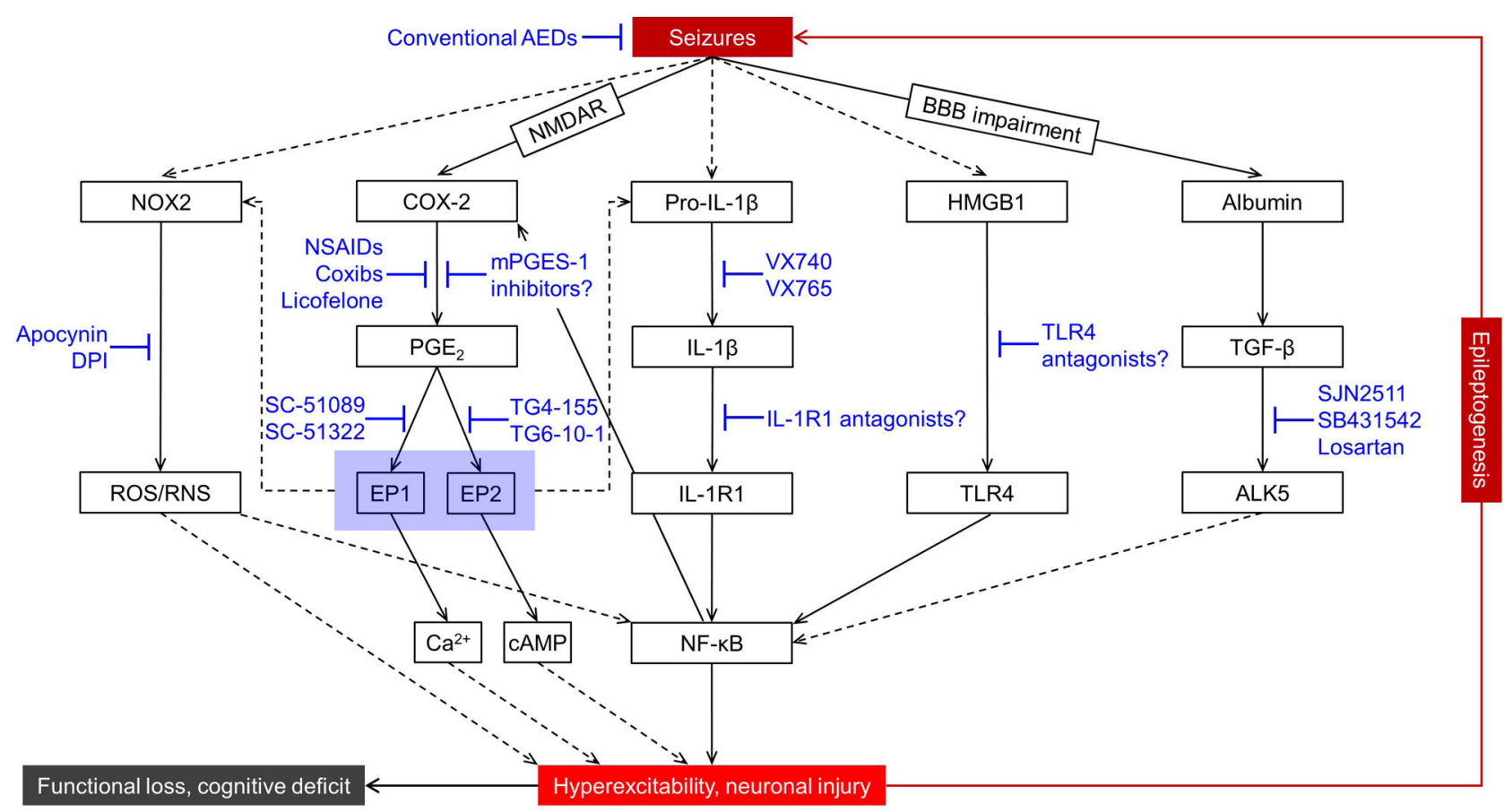

Figure 6.

Strategies of targeting inflammation to treat seizures and epilepsy. Inflammatory signaling pathways are upregulated by initial brain insults such as prolonged seizures and are proposed to contribute to the development of epilepsy. Only the major signaling pathways are indicated. AEDs alone cannot terminate the vicious circle of chronic inflammatory events that may lead to epileptogenesis. Small-molecule compounds that target the key proinflammatory mediators or their downstream signaling molecules might represent novel adjunctive strategies, along with AEDs and general anesthetics, to treat acute seizures and chronic epilepsy. Similar to IL-1 $\beta$, cytokines IL-6 and TNF-a also can induce COX-2 via $\mathrm{NF}-\kappa \mathrm{B}$ and facilitate excitotoxicity; however, small molecules that target these two proinflammatory mediators or their receptors are either not available or have not been tested in animal models for antiepileptic or antiepileptogenic effect. Abbreviations: AEDs, antiepileptic drugs; ALK5, activin-like kinase 5; BBB, blood-brain barrier; cAMP, cyclic AMP; COX, cyclooxygenase; Coxibs, COX-2 inhibitors; DPI, diphenyleneiodonium; HMGB1, high-mobility group box 1 protein; IL-1 $\beta$, interleukin-1 $\beta$; IL-1R, IL-1 receptor type 1; IL-6, interleukin-6; mPGES-1, microsomal prostaglandin E synthase-1; NF- $\kappa \mathrm{B}$, nuclear factor $\kappa \mathrm{B}$; NMDAR, $N$-methyl-D-aspartate (NMDA) receptor; NOX2, NADPH oxidase 2; NSAIDs, nonsteroidal anti-inflammatory drugs; ROS/RNS, reactive oxygen and nitrogen species; TGF- $\beta 1$, transforming growth factor- $\beta 1$; TLR4, toll-like receptor 4 ; TNF$a$, tumor necrosis factor- $a$. 


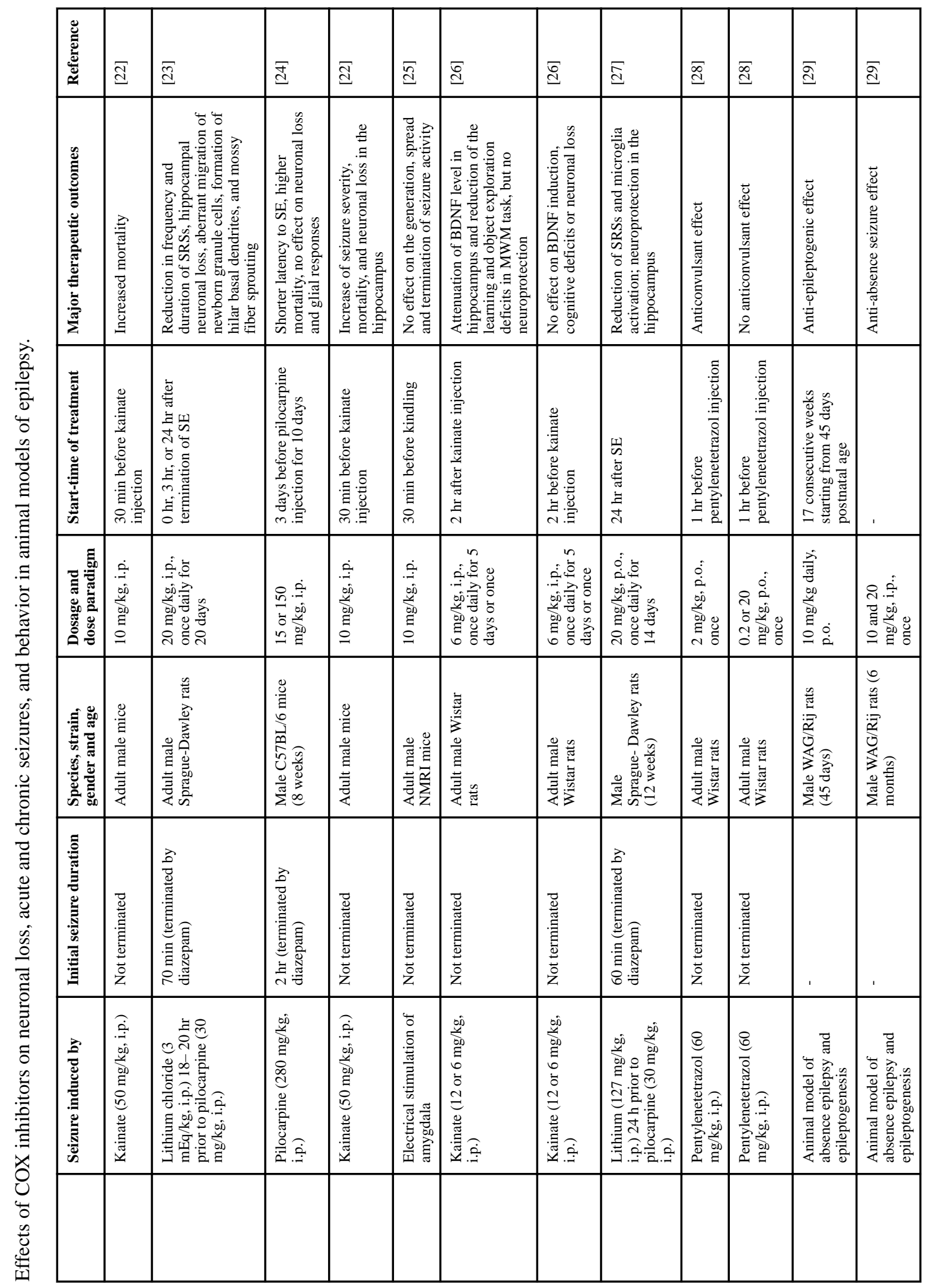

Trends Pharmacol Sci. Author manuscript; available in PMC 2017 June 01. 


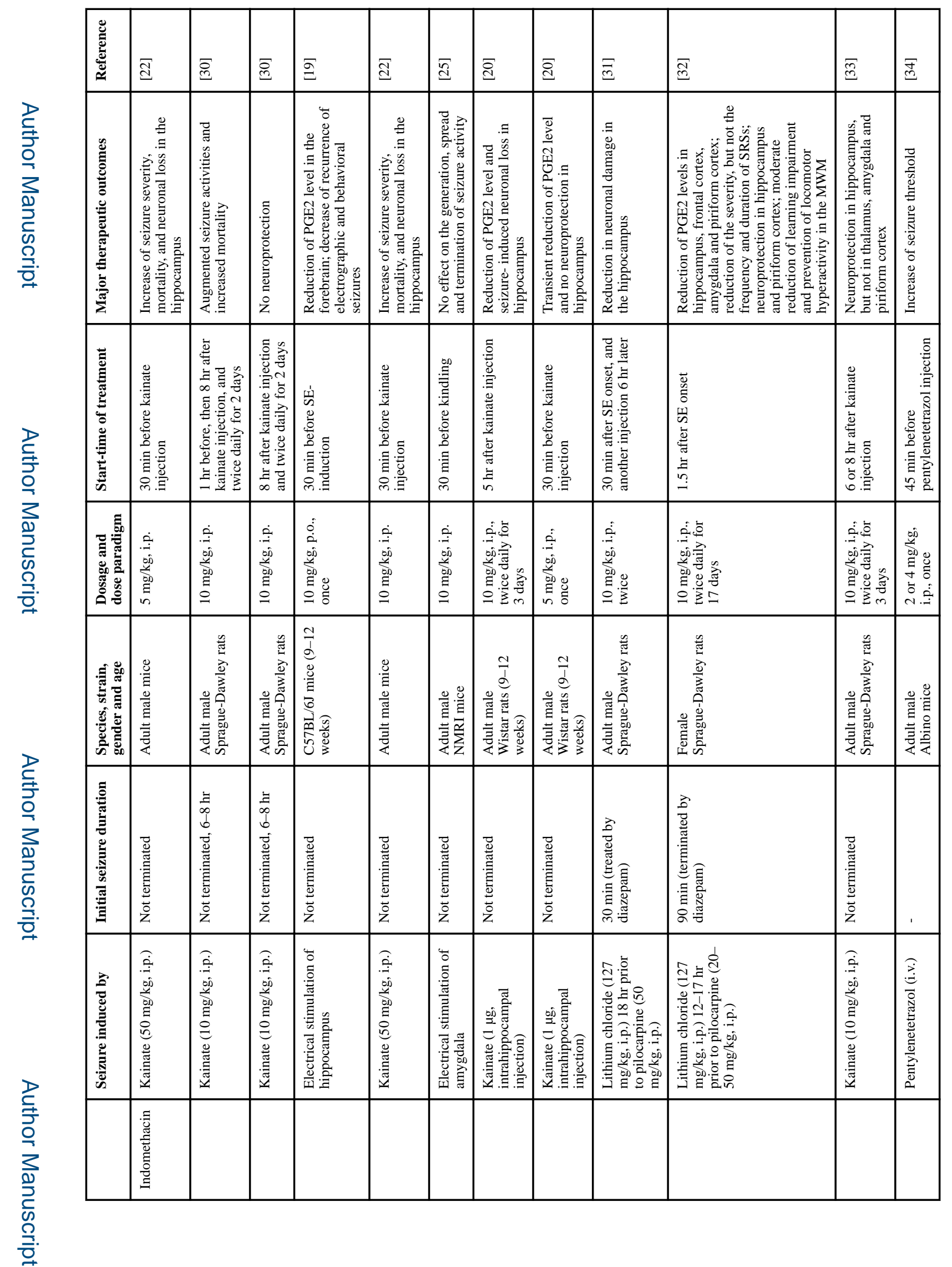

Trends Pharmacol Sci. Author manuscript; available in PMC 2017 June 01. 


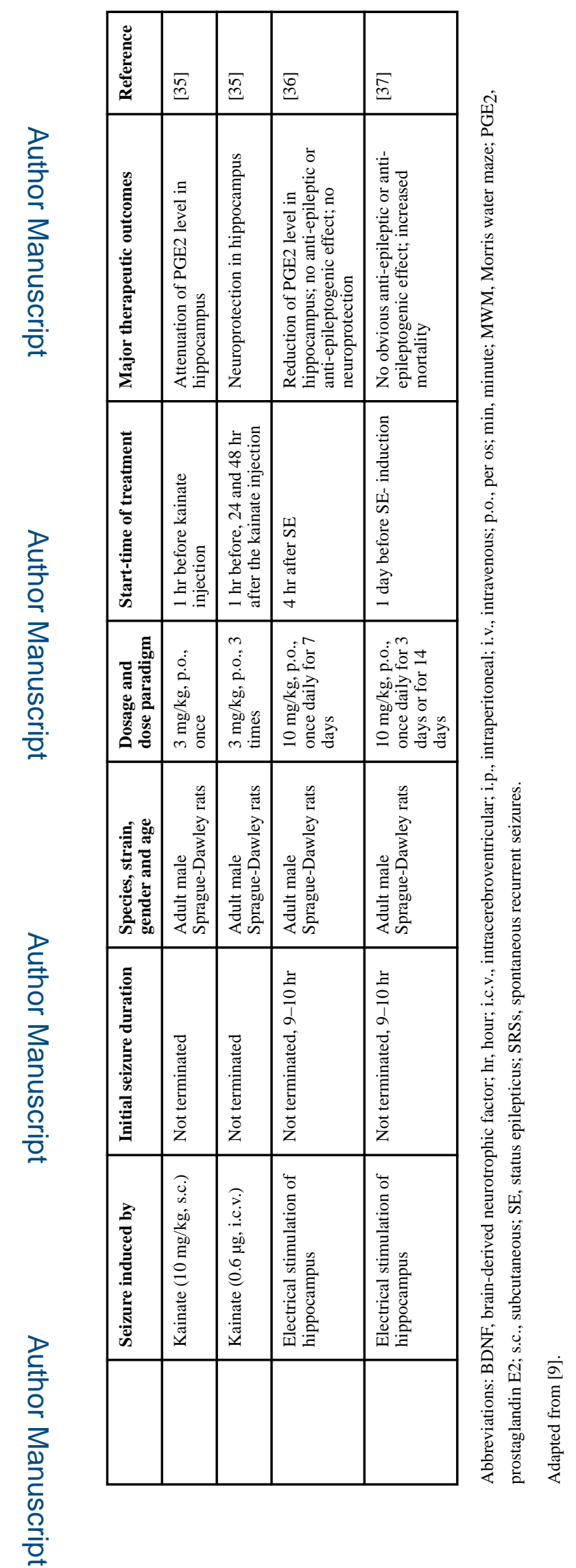

Trends Pharmacol Sci. Author manuscript; available in PMC 2017 June 01. 